\title{
HAY PARA TODOS. LA CIRCULACIÓN INTRA Y EXTRA-REGIONAL DE RÍO DE LA PLATA OBSERVADA DESDE LA ADUANA DE BUENOS AIRES, 1779-1783
}

\author{
THERE IS FOR EVERYONE. THE INTRA AND EXTRA-REGIONAL \\ CIRCULATION OF RÍO DE LA PLATA OBSERVED FROM THE CUSTOMS OF \\ BUENOS AIRES, 1779-1783
}

Fernando Jumar

CONICET / Inst. de Est. Históricos (UNTreF)

Academia Nacional de la Historia https://orcid.org/0000-0002-5926-5770 fjumar@conicet.gov.ar

\section{Resumen:}

El texto presenta un esquema general de la circulación vista desde la Aduana de Buenos Aires entre marzo de 1779 y diciembre de 1783 a través de una fuente rica en informaciones, las notas de aduana (y el libro de guías de aduana cuando faltan las primeras). Se propone que los datos aportados confirman hipótesis en torno a la existencia de un espacio económico rioplatense y se presenta una hipótesis sobre qué pueden estar revelando los bienes registrados en función de las sociedades involucradas a partir del consumo. El peso está puesto en la presentación de los datos generales, base de futuros trabajos centrados en algún circuito, en los bienes o en los actores del tráfico.

Palabras-clave: Río de la Plata; siglo XVIII; circulación interior; espacio económico.

\begin{abstract}
:
The text presents a general scheme of the circulation seen from the Customs of Buenos Aires between March 1779 and December 1783 through a rich source of information, customs notes (and the book of customs guides when there are notes missing). It is proposed that the data provided confirm hypotheses regarding the existence of a Rioplatense economic space and one is presented about what the registered assets may be revealing according to the societies involved from consumption. The weight is placed on the presentation of general data, basis of future work focused on some circuit, goods or traffic actors.
\end{abstract}

Keywords: Río de la Plata; XVIIIth century; inner circulation; economic space. 


\section{Introducción}

En Revolución y Guerra..., cuando se aborda la economía litoraleña en la vuelta del siglo XVIII al XIX, el papel del comercio en ella, las distintas esferas de la circulación y sus actores, así como los intereses puestos en juego Tulio Halperin Donghi se pregunta:

¿Es posible alcanzar una imagen cuantificada de este agitado proceso comercial? Para lograrla sería preciso un estudio necesariamente engorroso y prolongado de fuentes muy abundantes y de escasa densidad informativa, por otra parte considerablemente dispersas, desde las series aduaneras de Buenos Aires y Montevideo hasta los variados impuestos al comercio interno. Una investigación de estos alcances no podría ser encarada sino colectivamente. ${ }^{1}$

Se ha encarado ese estudio para un momento acotado, que gracias a la informática es menos engorroso de realizar que cuando se publicó el clásico citado (1972).

En este texto se presenta un esquema general de la circulación vista desde la Aduana de Buenos Aires entre marzo de 1779 y diciembre de 1783 a través de una fuente rica en informaciones, las notas de aduana (y el libro de guías de aduana cuando faltan las primeras). El peso está puesto en la presentación de los datos generales, base de futuros trabajos centrados en algún circuito, en los bienes o en los actores del tráfico. La crítica de los datos y la metodología empleada tornaban este texto demasiado extenso, con lo se publicarán en el próximo número de esta misma revista. ${ }^{2}$ En mi conocimiento, esas fuentes ya fueron trabajadas con objetivos similares para el período observado por Juan Carlos Garavaglia ${ }^{3}$ y Claudia Wentzel. ${ }^{4}$

\footnotetext{
1 Tulio Halperin Donghi, Revolución y guerra. Formación de una elite dirigente en la Argentina criolla, $1^{\mathrm{a}}$ ed. $1972,3^{\mathrm{a}}$ ed., Buenos Aires, Siglo XXI Editores S.A., 2002, p. 51.

2 Fernando Jumar, "En torno a la circulación observada desde la Aduana de Buenos Aires entre 1779 y 1783, en El taller de la Historia, 12, en prensa. Mientras se publica, el trabajo está disponible solicitándoselo por correo electrónico al autor. 3 Juan Carlos Garavaglia, "El comercio virreinal 1779-1784", Tesis de Licenciatura inédita, Universidad de Buenos Aires,1970,http://repositorio.filo.uba.ar/bitstream/handle/filodigital/4206/uba_ffyl_t_1970_se_Garavaglia. pdf? sequence=3\&isAllowed=y (consulta 10/03/2019). El trabajo citado es base de otro del autor: "El Río de la Plata en sus relaciones atlánticas: una balanza comercial (1779-1784)”, en Juan Carlos Garavaglia, Economía, sociedad y regiones, Buenos Aires, Ediciones de la Flor, 1987, pp. 65-117.

4 Existe una investigación inédita de 1989 producida por Claudia Wentzel para el período 1779-1810. Por los comentarios en la bibliografía, entiendo que se basa en las mismas fuentes que las utilizadas en este texto y que realiza sus análisis a partir de los precios de aforo. No he logrado acceder a ella. Claudia Wentzel, "Algunas consideraciones sobre el comercio de Buenos Aires con el Pacífico”, Buenos Aires, inédito, 1989. Sobre las cifras que presenta, C. S. Assadourian y Silvia Palomeque sostienen: "Es muy importante recuperar la serie construida por C. Wentzel sobre las importaciones de efectos ultramarinos que eran distribuidas por Buenos Aires, en tanto están en un trabajo inédito. Entre 1800 y 1813 Buenos Aires redistribuía un millón ochocientos mil pesos en Efectos de Castilla fuera de su propia región (Litoral y Paraguay), es decir en el Alto Perú, Chile, Cuyo y provincias del Interior. De ese total, 60\% aproximadamente iba hacia el Alto Perú
} 
La lectura se realiza tomando una herramienta de la economía espacial, el concepto de espacio económico, que en los problemas que me interesan se comenzó a utilizar a fines de los años 1960 para los dominios americanos ${ }^{5}$ de la Monarquía Hispánica y desde hace menos tiempo para los europeos ${ }^{6}$.

Las explicaciones abrevan en la bibliografía que se pregunta por la naturaleza de la dominación en la Monarquía Hispánica en los tiempos modernos desde la mirada posnacional, buscando puentes entre la renovación que se experimenta en ese campo de estudios desde la historia política desde los años $1990^{7}$ y las visiones consolidadas de larga data contenidas en la investigación sobre circuitos en los espacios estudiados ${ }^{8}$.

Dicho de otro modo, buscando puentes entre las explicaciones emergentes de investigaciones que se insertan dentro del paradigma jurisdiccional ${ }^{9}$ y las que lo hacen en términos analíticos el conjunto de pertenencia de los espacios abordados es el mundo

y Chile quedando sólo 40\% para el resto." Carlos Sempat Assadourian; Silvia Palomeque, "Los circuitos mercantiles del «interior argentino» y sus transformaciones durante la guerra de la independencia (1810-1825)", en Susana Bandieri (Coord.), La Historia económica y los procesos de independencia en la América Hispana, Buenos Aires, AAHE-Prometeo Libros, 2010, pp. 49-70, nota 2, p. 54. Se presentan gráficos emergentes del trabajo en Jorge Gelman; María Inés Moraes, "Las reformas borbónicas y las economías rioplatenses: cambio y continuidad", en Jorge Gelman; Enrique Llopis; Carlos Marichal (Coords.), Iberoamérica y España antes de las independencias, 1700-1820: crecimiento, reformas y crisis, México, Instituto de Investigaciones “Dr. José María Luis Mora”, 2014, pp. 31-74, passim.

5 Por Carlos Sempat Assadourian, por supuesto, y la gran cantidad de trabajos generados en su estela, como el presente. Para un seguimiento de esa bibliografía hasta el año 2011, v. Fernando Jumar, "El espacio colonial peruano en la historiografía sobre circulación mercantil", en História Ecônomica \& História de Empresas, 17, 2, 2014, pp. 475-534, http:// www.abphe.org.br/revista/index.php/rabphe/issue/view/40 (consulta 03/02/2019).

6 P.e. Guillermo Pérez Sarrión, La península comercial. Mercado, redes sociales y Estado en España en el siglo XVIII, Madrid, Marcial Pons Historia, 2012.

7 "Los estudios que vienen desarrollándose desde principios de la década de 1990 sobre el sentido, el desarrollo y la política de la Monarquía Hispánica han insistido en su estructuración como un conglomerado político fundado sobre entidades que prolongaban en parte - pero solo en parte- su autonomía medieval, y que sin embargo, gracias a la proyección exterior del poder del rey católico, pasaban a ser afectadas, de forma más o menos voluntaria, por los efectos de una proyección imperial que tenía mucho de global; unos efectos que tendían a activar procesos muy complejos de unificación fundados en la progresión fiscal, en la adopción de un lenguaje común inteligible para la corte y en la activación de mecanismos parecidos de incorporación de las elites y de los territorios dentro del servicio a la Monarquía." José Javier Ruiz Ibáñez, "Introducción: Las Monarquías Ibéricas y sus vecindades”, en José Javier Ruiz Ibáñez (Coord.), Las vecindades de las Monarquías Ibéricas, Madrid, Fondo de Cultura Económica, 2013, pp. 9-42, pp. 9-10.

8 De modo amplio, la gran mayoría son trabajos que directa o indirectamente (por abrevar en C. S. Assadourian) se insertan en los debates de los años 1960-1970 en torno del modo de producción americano. Aunque con diferencias por abordarse el problema desde distintos marcos teóricos, todas las variantes convergen en la inserción en el paradigma estatal/colonial.

${ }^{9}$ Existe una extensa bibliografía al respecto. Para síntesis del camino historiográfico de la renovación y su estado actual: Lidia Moriconi, Política, piedad y jurisdicción. Cultura jurisdiccional en la Monarquía Hispánica. Liébana en los siglos XVI-XVIII, Rosario, Prohistoria, 2011, pp. 31-56; María Inés Carzolio, "Estado, Estado moderno, cultura jurisdiccional y cultura constitucional”, en Eleonora Dell' Ellicine et al (Coords.), Pensar el Estado en las sociedades precapitalistas. Pertinencia, límites y condiciones del concepto de Estado, Los Polvorines, Universidad Nacional de General Sarmiento, 2012, pp. 125-138. La renovación parte de una crítica al paradigma estatalista en la historia europea, v. p. e. Jean-Frédéric Schaub, "Sobre el concepto de Estado", en Historia Contemporánea, 28, 2004, pp. 47-51; Francesco Benigno, Las palabras del tiempo. Un ideario para pensar históricamente, Madrid, Cátedra, 2013. 
hispánico. ${ }^{10}$ En cuanto a las dinámicas políticas de ese mundo se adhiere a las explicaciones que proponen que ya en los Reyes Católicos se observa una búsqueda por homogeneizar y centralizar la dominación en el conjunto. Camino interrumpido por la inclusión de los dominios de Castilla y Aragón en el Sacro Imperio, pero que es retomado desde Felipe II. ${ }^{11}$ Proyecto del actor 'Corona' que se mantiene de un rey a otro, de una dinastía a otra y se ejecuta en la medida que lo permiten las relaciones de fuerza con los otros poderes presentes en esa monarquía policéntrica. ${ }^{12}$ Desde esta perspectiva y en cuanto a intenciones, cabe tanto hablar de "reformismo Habsburgo" como de "reformismo Borbón". Felipe V, rey victorioso y con poder de fuego, abre una etapa de avance decidido de la vieja agenda de la Corona. ${ }^{13}$ Se comienza a buscar cambiar las formas, pasar de la monarquía compuesta a la administrativa, para transformar en profundidad lo que se comienza a llamar "la antigua constitución del reino", la monarquía polisinodal.

En relación con América, altos servidores de la Corona desde mediados de siglo XVIII comienzan a plantear un modo particular de absolutismo. Lo profundo del cambio buscado sin dudas es reflejo de la autonomía ultramarina. La transformación deseada es de reinos a 'colonias', dotándose ya la categoría del sentido que recogerá la historiografía. ${ }^{14}$ La idea se quiso aplicar, pero también estaban las agendas de los otros poderes de la Monarquía en sus diversos niveles, incluidas las de quienes no tenían más que el poder de la explosión de violencia para dar su opinión. También, los poderes de los vecinos, a uno y otro lado de mar. Del encuentro de todas esas agendas y la negociación emergen los procesos históricos que interesa abordar y que finalmente no responden de lleno a la agenda de ninguna de las voces del coro policentrado.

Así, como se observa en el trabajo de Javier Kraselsky, andando el siglo XVIII la Monarquía Hispánica, compuesta en la realidad, administrativa en las intenciones de la Corona y policéntrica en términos del poder genera la centralización corporativa como resultado no buscado por ningún actor en las negociaciones entre la Corona y actores

\footnotetext{
${ }^{10}$ No se encontró en la bibliografía que apela al concepto una definición rigurosa, pero de su lectura emerge que se compone del conjunto de dominios que en distintos momentos estuvieron reunidos en la soberanía de la corona de Castilla. Cuando se observa el conjunto desde la perspectiva policéntrica se lo suele llamar 'Monarquía Hispánica'. Sin dudas de inspiración braudeliana, la noción remite a un mundo analítico construido por la investigación en función del problema que se desea abordar. Ideas de base de las actuales historias conectadas, trasnacionales o globales. V. Sandra Kuntz Ficker, "Mundial, trasnacional, global: un ejercicio de clarificación conceptual de los estudios globales", Nuevo Mundo Mundos Nuevos, Debates, 2014, DOI: 10.4000/nuevomundo.66524 (consulta 02/02/2019).

${ }^{11}$ Antonio-Miguel Bernal, Monarquía e Imperio, Historia de España, Volumen 3, Barcelona, Crítica/Marcial Pons, 2007.

${ }^{12}$ P. e. v. Arrigo Amadori, Negociando la obediencia. Gestión y reforma de los virreinatos americanos en tiempos del conde-duque Olivares (1621-1643), Madrid, CSIC, 2013.

${ }^{13}$ Pedro Ruiz Torres, Reformismo e Ilustración, Historia de España, Volumen 5, Barcelona, Crítica/Marcial Pons, 2008.

${ }^{14}$ Miguel Artola, “América en el pensamiento español del siglo XVIII”, en Instituto Gonzalo Fernández de Oviedo, Homenaje a D. Ciriaco Pérez-Bustamante, Madrid, CSIC, 1969, pp. 51-78.
} 
locales que compiten entre sí por devenir su interlocutor privilegiado.

En el último cuarto del siglo XVIII y en temas económicos, entiendo que el resultado visible de la interacción de las agendas aludidas, tampoco buscado por nadie en particular, es que se estaba formando un gran mercado monárquico políticamente regulado. Así, el mundo hispánico mencionado antes podría ser visto desde lo económico como conformado por un conjunto de espacios económicos parcialmente superpuestos unos con otros, pero raramente todos entrelazados en primer grado, a no ser por la presencia de tres actores comunes a todos: la Corona, las redes mercantiles y las redes eclesiales ${ }^{15}$. Los complejos productivos señalados por la circulación revelarían diversos centros emergentes del juego de fuerzas económicas y/o de intentos de creación desde la Corona. El policentrismo que señala la historia social del poder en la Monarquía Hispánica muestra que las permanentes negociaciones fiscales llevan a una liberalización progresiva del tráfico interior sobre la base de una suerte de división monárquica del trabajo, y cerrazón hacia el exterior en la medida de lo posible, en general apelando a discursos que proponen fomentar la producción interna. ${ }^{16}$ Maximiliano Camarda en este dossier marca el recorrido que lleva a esta configuración desde el punto de vista de los circuitos ultramarinos.

De ese conjunto de mercados que habrían compuesto el mundo hispánico interesa aquí en particular un hipotético espacio económico rioplatense y las regiones que lo habrían compuesto (en especial su cabecera, la región Río de la Plata). En el mundo hispánico Río de la Plata es una de las fronteras que merecen atención, actúa como articulador entre espacios americanos y europeos y es un espacio valioso en sí en lo económico. ${ }^{17}$ Todos los trabajos reunidos en este dossier confirman desde diversos ángulos estas hipótesis compartidas.

En este texto en particular, se propone un conjunto de hipótesis en torno a la organización espacial de los intercambios, las intensidades y densidades de las relaciones

\footnotetext{
${ }^{15}$ Las redes eclesiales no formaban parte de la primera modelización. Agradezco a mis alumnos de la UNTreF, año 2018, haberme hecho notar el error.

${ }^{16}$ El argumento se desarrolla en Fernando Jumar, "El mundo hispánico durante el Antiguo Régimen desde los circuitos mercantiles y el espacio económico rioplatense”, en Historia Crítica, 70, 2018, pp. 23-44, https://doi.org/10.7440/ histcrit70.2018.02 (consulta 15/01/2019).

${ }^{17}$ Mutatis mutandis se asemeja a Veracruz, con su economía regional engarzada con la función portuaria y todo lo que estaba en juego con su control (Antonio García de León, Tierra adentro, mar en afuera. El puerto de Veracruz y su litoral a sotavento, 1519-1821, México, Fondo de Cultura Económica/Gobierno del Estado de Veracruz/Universidad Veracruzana, 2011). También al complejo portuario andaluz (Pierre Chaunu, Sevilla y América, siglos XVI y XVII, Sevilla, Universidad de Sevilla, 1983), a Cartagena de Indias en su función estructuradora de circuitos interiores (Maribel de la Cruz-Vergara, "Fluvial and maritime commerce through the Port of Cartagena de Indias as conciliatory element in the Viceroyalty of Nueva Granada's economy, 1780-1810, en The Latin Americanist, 60, 20, 2016, pp. 191-216) o a los puertos del Pacífico en la perspectiva que los analiza Guadalupe Pinzón (Guadalupe Pinzón Ríos, Acciones y reacciones en los puertos del Mar del Sur. Desarrollo portuario del Pacífico novohispano a partir de sus políticas defensivas, 17131789, México, UNAM/Instituto Mora, 2011). En fin de cuentas, los puertos son más parecidos entre ellos que cada uno con su respectivo traspaís.
} 
con Buenos Aires, el lugar que ocupan las regiones para el puerto y el tipo de articulación que podría estar observándose. María Claudia Errecart muestra en el dossier los soportes materiales de los tratos, al observar los caminos en función de ellos y los medios de transporte, para centrarse en los transportistas.

Las cifras obtenidas en relación con la circulación para los años observados, 1779-1783, inclusive criticadas en función de la coyuntura y su representatividad ${ }^{18}$, sugieren algunas ideas nuevas y comprometen otras consolidadas. Se aleja la explicación "colonial" de la naturaleza de las relaciones mercantiles. Las conexiones con el Alto Perú no son las más relevantes, lo que llevó a José Sovarzo a analizar la ruta del Oeste, que vincula el Atlántico y el Pacífico sur, más todas las economías americanas intermedias y parece ser la principal para el puerto rioplatense. Circulan en todas direcciones tantos y tan variados bienes, algunos en grandes cantidades, que invitan a hacerse preguntas. Así, en relación con los bienes transados y ante las cifras obtenidas y su crítica, se intenta abordar el problema desde la demanda en las sociedades americanas observadas y se pone el acento en una hipótesis relacionada con un consumo estamental, que señala elementos de la estratificación social de las sociedades americanas hacia adentro. Ana Clara Gastaldi y Mariel Esjaita hacen el balance sobre el problema del consumo en la historiografía hispanoamericanista y delinean estrategias para analizarlo por lo alto y por lo bajo de la sociedad.

Además de esta Introducción, el texto presenta los datos generales obtenidos en relación a la salida de bienes desde Buenos Aires debidamente registrados en su Aduana, así como su organización en función de la circulación intra y extra-regional. Estos análisis dan el contexto de la lectura propuesta, que se retoma en las Conclusiones.

\section{La circulación mostrada por las notas de aduana, 1779-1783}

El universo de observación está compuesto por 17.382 notas de aduana para el período marzo de 1779 a diciembre de 1783 , que contienen 112.790 registros de bienes ${ }^{19}$ con diversas cantidades de cada uno. La Tabla 1 (al final del texto) muestra los criterios de clasificación utilizados y las Tablas 2 (a y b, al final del texto) los correspondientes a las agrupaciones espaciales.

Las notas de aduana registran diversos tipos de movimientos, que no siempre se relacionan con la venta de lo declarado. Dado que no es el objetivo en este trabajo abordar

\footnotetext{
${ }^{18}$ F. Jumar, "En torno a la circulación".

${ }^{19}$ En función de las informaciones retenidas para cada registro de bienes se tiene una base con 3.681 .446 datos a explotar. Registros de Aduana de Antiguo Régimen, base de datos marzo de 1779 a diciembre de 1783 recopilada a partir de las notas de aduana registradas en la Aduana de Buenos Aires, Archivo General de la Nación, Argentina, XIII-14-9-1; 14-9-5; 33-11-2; 33-11-3; 34-1-5; 34-2-1; 34-2-5; 34-3-1; 34-4-1; 34-4-2; 34-1-5. En adelante RegAduAR. La fuente y su tratamiento se aborda en: F. Jumar, "En torno a la circulación”.
} 
la circulación mercantil en particular sino las articulaciones espaciales, no se realizan discriminaciones al respecto y en la medida que la fuente lo permite. Sin embargo, no está de más señalar que la gran mayoría de lo registrado parece circular con fines mercantiles. En el conjunto se mezclan operaciones de actores que fueron a proveerse en el puerto y se regresan a sus moradas con negocios emprendidos desde allí por comerciantes locales (muchas veces actuando en tanto que comisionistas) y forasteros (que se terminan radicando en alguno de los mercados visitados o se regresan a Europa con parte de los beneficios y dejando muchas deudas por cobrar a cargo de comisionistas).

Una primera observación que se puede hacer de los datos, muy general, es la distribución por año de las cantidades de notas y de registros de bienes en cada una, en general y por circuitos.

La cantidad de notas de aduana con destino en uno u otro espacio permite observar grados de integración en y entre mercados. La idea es simple: se está ante un conjunto de mercados entrelazados y parcialmente superpuestos; una mayor cantidad de contactos revela vinculaciones fluidas, caminos y transportistas, buena circulación de la información, regularidad en el entrelazamiento de actores y demás variables que permiten pensar en bajos costos de transacción, manejables para más actores, que es una variable central en las economías observadas. ${ }^{20}$ Como ya se mencionó, en este dossier María Claudia Errecart tras pasar revista a los caminos que articulan los espacios, con sus dificultades, beneficios e imposiciones en relación a los medios de transporte, centra la mirada en los contactos para observar a uno de los actores del tráfico, los transportistas, agentes centrales de los procesos de integración.

Trasladando nociones de análisis de redes de relaciones interpersonales, la cantidad de contactos muestra la intensidad de las relaciones y señalan si hay o no un entramado sólido en el que se desarrollan los tratos.

Además, se puede observar la cantidad de registros de bienes contenidos en cada nota de aduana, la cantidad de cada uno y/o su valor. Estas variables dan distintos indicios sobre la densidad de esos tratos. En este texto se utiliza sobre todo el dato de la cantidad de registros de bienes contenidos en cada nota de aduana y en menor medida la cantidad de cada bien.

${ }^{20}$ Jean-Yves Grenier, “Modèles de la demande sous l'Ancien Régime”, en Annales ESC, 3, 1987, pp. 497-527; L'économie d'Ancien Régime. Un monde de l'échange et de l'incertitude, París, Alban Michel, 1996. 
Tabla 3. Intensidad y densidad de los tratos. Notas de Aduana. Aduana de Buenos Aires.

\begin{tabular}{|l|r|r|r|r|r|r|}
\cline { 2 - 7 } \multicolumn{1}{c|}{} & \multicolumn{1}{c}{1779} & \multicolumn{1}{c}{1780} & \multicolumn{1}{c}{1781} & \multicolumn{1}{c}{1783} & \multicolumn{1}{c|}{ Total } \\
\hline \multirow{nyyyyyy}{c}{ Intensidad } & 3.215 & 3.643 & 2.927 & 3.573 & 4.024 & 17.382 \\
\cline { 2 - 7 } Densidad & 27.524 & 24.141 & 17.495 & 18.732 & 24.898 & 112.790 \\
\hline
\end{tabular}

Fuente: RegAduAR.

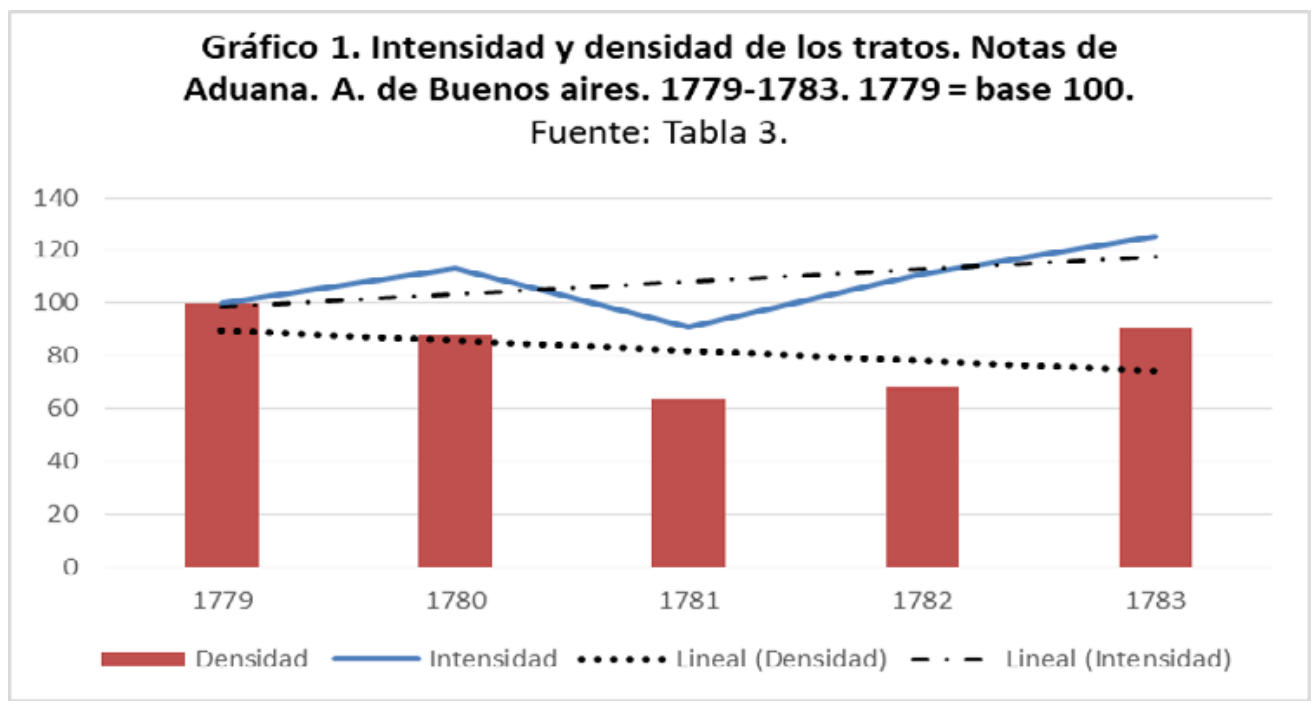

La Tabla 3 y el Gráfico 1 muestran a grandes trazos en el conjunto de circuitos anudados en el complejo portuario rioplatense la doble perturbación esperada por la coyuntura (la guerra anglo-española de 1779-1783 y las rebeliones altoperuanas de 1780-1781). La turbulencia no llegó a afectar seriamente la intensidad (lo que podría haber desarticulado el circuito). Las tendencias de ambas series de datos pueden indicar que el principal impacto fue en la reducción de la densidad (cantidad de registros de bienes) y aumento de la intensidad (cantidad de contactos). Puede ser un comportamiento esperable en una coyuntura compleja. Tal vez haya una retracción de los grandes y negocios más chicos en manos de quienes ven en el riesgo una oportunidad. La densidad muestra claramente algún tipo de contracción de la circulación, con una tendencia que a pesar de la recuperación en las cantidades absolutas desde 1782, no llega al nivel de partida de la observación en 1779.

Tal vez lo que haya que explicar es el abultado año 1779, más aún si se tiene en cuenta que no se encontraron 465 notas de aduana de enero y febrero de ese año, para entender mejor la alicaída tendencia al finalizar la serie de datos.

En efecto, a partir de la contextualización del período ${ }^{21}, 1779$ en Río de la Plata tiene todo lo necesario para ser un muy buen año, tanto para los negocios como para la capacidad

${ }^{21}$ F. Jumar, "En torno a la circulación”. 
de la Corona por concentrar la circulación por su circuito legal (fraude siempre hay ${ }^{22}$ ) y hacer avanzar su agenda en la región. Esto último no se debe solamente a la expedición de Cevallos, es tan importante para ello la alianza establecida con el comercio porteño que da frutos de modo inmediato. ${ }^{23}$ Pero los viejos usos, la cultura arraigada resiste y María Evangelina Vaccani nos muestra comportamientos muy poco "borbónicos" de individuos que se resisten a ser "funcionarios" de una Real Aduana que costó imponer, para seguir siendo servidores de la Corona que terminan fagocitados por las redes de poder local. Como en el siglo XVII. Lo diferente ahora es que la Corona no renuncia fácilmente y vuelve a la carga, pero lo mejor que obtiene es la centralización corporativa que propone Kraselsky, que en el fondo contiene el germen de la disolución porque da nuevos canales de expresión a los poderes locales. ${ }^{24}$

Sin hacer un análisis mensual en el que se puedan percibir momentos precisos de impacto de los acontecimientos en los mercados, en 1779, aun si desde junio discretamente el virrey pone trabas a la salida de navíos por la guerra contra Gran Bretaña, la circulación intrarregional todavía goza del doble efecto revitalizador de la economía regional que significó la expedición de Cevallos ${ }^{25}$ y el primer rush derivado de la liberalización

\footnotetext{
${ }^{22}$ Un posible caso: Por un lado, Francisco Vargas registra 25 ponchos para Montevideo en agosto de 1781, aforados en 12 reales cada uno (RegAduAR, nota 2.010/1782). Por otro lado, aparece comprando 26 ponchos a Marcelino Callexas Sanz y Ca a 11 reales cada uno, pagados en febrero de 1782 (Archivo Histórico de la Provincia de Buenos Aires (en adelante AHPBPA), 7-5-6-5. Libro de caja perteneciente a dn Marcelino Callexas Sanz y dn Ramón García Pérez, y da principio en 6 de Noviembre de 1780. Libro Primero, fo 2vta). O bien Vargas vendió un poncho antes de salir de Buenos Aires, o el fardo que presentó en la Aduana tenía un poncho no declarado que pasó porque tal vez el vista no verificó y se dejó guiar por el uso de que un fardo con ponchos contenía 25 unidades. Además, se ve en este caso que el valor de aforo fue mayor que el precio pagado.

${ }^{23}$ Javier Kraselsky, "Las estrategias de los actores del Río de la Plata: las Juntas y el Consulado de comercio de Buenos Aires a fines del Antiguo Régimen (1748-1809)", Tesis de Doctorado inédita, Universidad Nacional de La Plata, 2011.

${ }^{24}$ En el caso rioplatense, presiones del gremio de Hacendados en dirección de la creación de la Hermandad de la Mesta en la región (1792) se relacionan con su inclusión en 1797 en el Consulado creado en 1794. De este modo, una institución originalmente concebida por los comerciantes que desde Río de la Plata buscan controlar los flujos regionales y mejorar sus condiciones relativas de negociación con los productores y prestatarios de servicios (incluidos los rioplatenses), deben incluir en su matrícula a los hacendados de una de esas regiones y alternarse con ellos en la dirección de la corporación. Así, grupos que se vienen oponiendo desde mediados del siglo a través de sus respectivos gremios y compitiendo entre sí pos devenir el interlocutor privilegiado de la Corona, se ven reunidos en un órgano local en el que deberán dirimir sus diferencias y presentar un frente común, cuando es posible, ante los avances de la monarquía administrativa. Fernando Jumar; Javier Kraselsky, "Las esferas del poder. Hacendados y comerciantes ante los cambios de la segunda mitad del siglo XVIII”, en Anuario del Instituto de Historia Argentina, Universidad Nacional de La Plata, 7, 2007, pp. 31-58.

${ }^{25}$ La expulsión de la presencia portuguesa en Colonia del Sacramento que concentra los flujos en el circuito español cuando todavía no cabe esperar una presencia importante de navíos del comercio directo que la reemplace. La enorme dinamización para la economía regional provino de tener de golpe (además de los navíos del comercio presentes), 116 barcos del servicio real y 9.038 hombres que atender y devolver al Atlántico. Sobre el impacto económico de la expedición ver: Rubén Darío Serrato Higuera, "Las armas del dinero: mecanismos de financiación y administración en la segunda expedición de Pedro de Cevallos al Río de la Plata, 1777”, Tesis de Maestría, Universidad Nacional de Tres de Febrero, 2017; existe una versión publicada: Las armas del dinero. El estado fiscal-militar español del siglo XVIII, Saarbrücken, Editorial Académica Española, 2018.
} 
del tráfico con Río de la Plata en febrero (y no en octubre) de 1778, visible en el texto de Maximiliano Camarda a través de los datos del movimiento ultramarino del complejo portuario rioplatense. En los años siguientes, además del impacto por las perturbaciones, las cifras pueden señalar también el inicio de una búsqueda de equilibrios entre oferta y demanda. ${ }^{26}$ Otra cosa que muestran los datos de 1779 es que el Auto de Libre Internación de 1777 se montó sobre articulaciones previas, porque parece poco probable que en tan poco tiempo se hayan armado las redes que permitan tal presencia en Norte si se partía de un nivel muy bajo, formalmente casi inexistente. La economía regional florece, como muestran Nicolás Biangardi desde el complejo productivo y María Emilia Sandrín desde el de servicios. La sociedad cambia al mismo ritmo que su economía, lo nuevo y lo viejo se ve en los trabajos de historia social que aportan José Bozzo y Josefina Mallo. Comerciantes que no llegan a burgueses y acumulan para ennoblecerse. Mulatos que vienen de la primera mitad del siglo, entroncados con una familia benemérita que los legitima, llegan finalmente a ser "dones" con una base de inconmovibles valores de Antiguo Régimen a la hora de regular sus relaciones familiares y sus aspiraciones.

Se puede refinar la observación de las cifras a través de la distribución por circuitos. Antes de hacerlo, es necesario presentar una decisión metodológica ya que supuso una intervención sobre los datos.

Las notas registradas para la ciudad de Córdoba presentan cierta complejidad. Como es sabido, Córdoba además de atender su consumo, también es un importante nodo de redistribución. ${ }^{27}$ Hacia dentro de su jurisdicción, hacia los otros espacios de Centro, el Norte y el Oeste, tal como se observa en los trabajos de Carlos Sempat Assadourian y Silvia Palomeque, juntos ${ }^{28}$ o $\operatorname{separados}^{29}$, así como en los de Ana Inés Punta ${ }^{30}$ y Silvia

\footnotetext{
${ }^{26}$ También ajustes en la oferta en función de la demanda por parte de los nuevos interlocutores peninsulares producto de la multiplicación de puertos habilitados para entrar en contacto directo con los americanos, lo que reduciría la variedad en los registros de bienes. P. e. en 1780-1783 dos jóvenes y nóveles comerciantes asentados recientemente en Río de la Plata no dejan de advertir a sus interlocutores en Galicia que están enviando "maulas" (mercaderías invendibles) que no se ajustan a los gustos locales. Se las devuelven junto con listados de los bienes más requeridos. V. F. Jumar, “«Buscar la vida» en el Río de la Plata. Marcelino Callexas Sanz, 1757-1820, en Illes i Imperis, 18, 2016, pp. 44-76.

${ }_{27}$ Tampoco hay que olvidar, que tanto para su consumo como para redistribuir, el mercado cordobés no se suple sólo desde Buenos Aires, sino también desde el Pacífico, pero no es algo que preocupe ahora.

${ }^{28}$ Carlos Sempat Assadourian; Silvia Palomeque, "Las relaciones mercantiles de Córdoba (1800-1830). Desarticulación y desmonetización del mercado interno colonial en el nacimiento del espacio económico nacional”, en María Alejandra Irigoin; Roberto Schmit (Eds.), La desintegración de la economía colonial. Comercio y moneda en el interior del espacio colonial (1800-1860), Buenos Aires, Biblos, 2003, pp. 151-225.

${ }_{29}$ Carlos Sempat Assadourian, El sistema de la economía colonial. El mercado interior, regiones y espacio económico, Lima, IEP, 1982; Silvia Palomeque, "La circulación mercantil en las provincias del Interior argentino entre 1800 y 1810", en Anuario IEHS, 4, 1989, pp. 131-210; Silvia Palomeque, "Circuitos mercantiles de San Juan, Mendoza y San Luis. Relaciones con el «interior argentino», Chile y el Pacífico sur (1800-1810)", en Anuario IEHS, 21, 2006, pp. $255-281$.

${ }^{30}$ Ana Inés Punta, Córdoba borbónica. Persistencias coloniales en tiempos de reformas (1750-1800), 2da. edición, Córdoba, Universidad Nacional de Córdoba, 2010.
} 
Romano. ${ }^{31}$ Para dar una ilusión de precisión a los envíos de Buenos Aires a Córdoba una solución posible es dividir las notas registradas a la ciudad en cuatro partes y asignar una al Oeste, otra al Norte y las dos restantes al propio Centro para atender su propio consumo. ${ }^{32}$ Tan salomónica como arbitraria, la operación se justifica en la necesidad de no ignorar una realidad cuya importancia ha sido puesta de manifiesto en investigaciones sólidas.

Sin lugar a dudas, se aplican a Salta y Jujuy en Norte, a Mendoza y San Juan en Oeste y a Asunción en Paraguay las mismas prevenciones sobre qué revelan las notas de aduana en relación a funciones redistribuidoras de esas ciudades. Sin embargo, en estos casos no se consideró necesario intentar corregir los datos ya que las redistribuciones realizadas son dentro de los mismos circuitos en los que están integradas, con lo que se puede llevar a cabo sin inconvenientes la observación deseada. Otro tanto pasa con Tucumán ${ }^{33}$ y seguramente Santiago del Estero ${ }^{34}$.

Tabla 4, a y b. Aduana de Buenos Aires. Notas de aduana. Intensidad y densidad de los tratos registrados. Circulación intra e extra-regional. 1779-1783

\begin{tabular}{|c|c|c|c|c|c|c|c|c|}
\hline a. Intensidad & 1779 & 1780 & 1781 & 1782 & 1783 & Total & \% Extra-r. & $\%$ s/total \\
\hline 01. Centro & 135 & 156 & 97 & 132 & 172 & 692 & $14,12 \%$ & $3,98 \%$ \\
\hline 02. Norte & 175 & 170 & 103 & 186 & 385 & 1.019 & $20,79 \%$ & $5,86 \%$ \\
\hline 03. Oeste & 330 & 477 & 353 & 473 & 652 & 2.285 & $46,61 \%$ & $13,15 \%$ \\
\hline 04. Paraguay & 166 & 187 & 192 & 185 & 177 & 906 & $18,48 \%$ & $5,21 \%$ \\
\hline Sub-total extra-r. & 806 & 990 & 745 & 976 & 1.386 & 4.902 & $100,00 \%$ & $28,20 \%$ \\
\hline 05. Río de la Plata & 2.409 & 2.653 & 2.182 & 2.597 & 2.638 & 12.480 & & $71,80 \%$ \\
\hline Total & 3.215 & 3.643 & 2.927 & 3.573 & 4.024 & 17.382 & & $100,00 \%$ \\
\hline
\end{tabular}

\begin{tabular}{|c|c|c|c|c|c|c|c|c|}
\hline b. Densidad & 1779 & 1780 & 1781 & 1782 & 1783 & Total & \% Extra-r. & $\% \mathrm{~s} /$ total \\
\hline 01. Centro & 2.970 & 1.363 & 780 & 1.004 & 2.089 & 8.206 & $17,06 \%$ & $7,28 \%$ \\
\hline 02. Norte & 3.689 & 1.632 & 730 & 2.074 & 5.777 & 13.902 & $28,90 \%$ & $12,33 \%$ \\
\hline 03. Oeste & 3.445 & 3.141 & 1.960 & 2.357 & 5.320 & 16.223 & $33,73 \%$ & $14,38 \%$ \\
\hline 04. Paraguay & 2.370 & 1.975 & 1.987 & 1.423 & 2.010 & 9.765 & $20,30 \%$ & $8,66 \%$ \\
\hline Sub-total extra-r. & 12.474 & 8.111 & 5.457 & 6.858 & 15.196 & 48.096 & $100,00 \%$ & $42,64 \%$ \\
\hline 05. Río de la Plata & 15.050 & 16.030 & 12.038 & 11.874 & 9.702 & 64.694 & & $57,36 \%$ \\
\hline Total & 27.524 & 24.141 & 17.495 & 18.732 & 24.898 & 112.790 & & $100,00 \%$ \\
\hline
\end{tabular}

Fuente: RegAduAR.

Así, según los parámetros establecidos, la Tabla 4 muestra que la circulación extra-regional (Centro, Norte, Oeste, Paraguay) es revelada por 4.902 notas $(28,2 \%)$, que conciernen 48.096 registros de bienes (42,64\%). La circulación intrarregional rioplatense

${ }^{31}$ Silvia Romano, “Córdoba y el intercambio regional, 1820-1855”, en Cuadernos de Historia, Serie Economía y Sociedad, 2, 1999, Universidad Nacional de Córdoba, Área de Historia del CIFFyH, 1999, p. 151-182.

${ }^{32}$ Para simplificar las tablas y trabajar con números enteros, los decimales de la división de los impares en cuatro partes se asignaron a Norte.

${ }^{33}$ Cristina López de Albornoz, “Tiempos de cambio: producción y comercio en Tucumán (1770-1820)", en Andes, 13, 2002, sin paginación (33 pp.), http://www.redalyc.org/articulo.oa?id=12701308 (consulta 12/o3/2019).

34 P. e. María Mercedes Tenti de Laitán, "El comercio de La Rioja y Santiago del Estero en la época virreinal”, en Nuevas Propuestas. Revista de la UCSE, 19, 1996, pp. 67-78. 
suma 12.480 notas $(71,8 \%)$, con 64.694 registros de bienes $(57,36 \%)$, pero con una gran salvedad: las notas muestran de modo directo lo que salía de Buenos Aires pero ocultan el comercio en la ciudad. Además, no se han procesado aún las notas de Montevideo y de las receptorías menores (principalmente Riachuelo y Las Conchas sobre la banda sur y Colonia y Maldonado sobre la banda norte). Ello silencia la redistribución de Montevideo hacia su traspaís y las conexiones entre puertos menores que revelarán micromovimientos. El primer sondeo de tales fuentes muestra que sus datos impactan sobre todo la circulación intrarregional y de la extra-regional, en la ultramarina. De modo que cabe esperar que las cifras totales emergentes de las receptorías de todo el complejo portuario rioplatense aumenten el desbalance en favor de la circulación intrarregional.

Aún con los datos faltantes domina ampliamente la circulación intrarregional. La distancia en la intensidad de contactos hacia dentro y hacia afuera señala una economía regional rioplatense más próspera que las otras, o que no es alimentada por otros circuitos legales e ilegales en el nivel que tendrían que estarlo las otras regiones para equiparar su consumo con el rioplatense, a través de los bienes que en esta investigación no se ven circular $^{35}$. Río de la Plata no es la única proveedora, de modo que lo que se observa con estos datos es lo que esas regiones representan para Río de la Plata. Lo que representa Río de la Plata para ellas y el cuadro completo de cada espacio se podrá clarificar con el cruce de datos de la bibliografía que analiza otras regiones y mira el conjunto en el que se insertan desde ellas.

\section{La circulación extra-regional}

La circulación extra-regional de Río de la Plata hacia el interior americano visible en las fuentes consultadas ${ }^{36}$ es la que se dirige a Centro, Norte, Oeste y Paraguay (V. Mapa 1 al final del texto).

Por la fuente utilizada no es posible afirmar, salvo en casos específicos ${ }^{37}$, que el destino físico declarado del movimiento es el del consumo final de los bienes concernidos. Lo que se observa son las rutas troncales y en mucha menor medida sus ramificaciones

\footnotetext{
${ }^{35}$ No sólo los relacionados con el comercio ilegal, sino también los que ingresaban en los mercados por otros canales del comercio legal español desde el Pacífico sur o por el Alto Perú.

${ }^{36}$ Ciertamente, no se ve nada de lo que pudo ser remitido a los dominios portugueses, por tierra o por agua, salvo unas notas que se registran en 1779 y 1780 para ser embarcadas con destino en Brasil y que se relacionan con antiguos habitantes de Colonia de Sacramento que finalmente no permanecen en la región.

37 Notas registradas que incluyen datos sobre el consumo de los bienes, generalmente del causante, su familia o establecimientos productivos. También, aprovisionamiento/reparación denavíos (civiles y militares); aprovisionamiento de soldados, instituciones religiosas, servidores de la corona y/o las dependencias en las que trabajan.
} 
dentro de cada espacio regional (cuando desde alguno de esos puntos se mantienen tratos directos con Buenos Aires, o cuando desde Buenos Aires se remiten bienes a un punto troncal indicándose que deben re-expedirse a otro sitio).

En Norte se incluyen las notas registradas para diversos puntos del Alto Perú (o a los que se llega por su intermedio) ${ }^{38}$ así como para las ciudades de Salta, Jujuy y una cuarta parte de las destinadas a la ciudad de Córdoba. En las relaciones interregionales rioplatenses, Norte recibe 5,86\% del total de notas o 20,79\% de las interregionales, que contienen $33,73 \%$ de las cantidades de bienes registrados hacia los mercados interiores o 12,33\% del total (Tabla 4). Si se comparan los datos con los de las otras rutas, Norte parece ser una más entre las que se anudan en Río de la Plata. Si es el caso, tal vez la pregunta central sea por qué caminos llegaron a Río de la Plata los millones de pesos con los que compensó sus cuentas con el comercio ultramarino, legal e ilegal. A menos que el de Norte fuese un comercio de poca intensidad y densidad, pero de muchísimo valor. Pero el contenido de los registros de bienes no difiere del de los otros circuitos, de modo que parece poco probable.

Alto Perú muestra contactos aislados con varios destinos, que en algunos casos de modo seguro tienen detrás historias que no se relacionan con la circulación comercial. ${ }^{39}$ Sin sorpresas, los puntos más enlazados son Potosí, La Plata y La Paz, que en conjunto suman 375 notas de aduana de las 419 remitidas al Alto Perú o por la vía del Alto Perú. Se esperaba ver más contactos directos con Cochabamba (hay cuatro), como respuesta a sus envíos de tocuyos.

Salta y Jujuy confirman lo sabido sobre su papel en la redistribución, ya que parece poco probable que sus mercados locales pudieran dar salida a lo allí enviado. Es por allí que los tocuyos entran en los circuitos del sur, como los bienes que llegan desde allí en

\footnotetext{
${ }_{38}^{38}$ Azángaro, Carabaya, Chayanta, Chicas, Chucuito, Chulumani, Cochabamba, Cuzco, La Paz, La Plata, Lampa, Oruro, Potosí, Puno, Santa Cruz de la Sierra, Santa Rosa de Ocopa, Tarija, Tomina, Yamparaes.

${ }^{39}$ P. e. en 1779 se registra el único contacto de Buenos Aires con el colegio franciscano de Santa Rosa de Ocopa (Arzobispado de Lima), por la ruta del Alto Perú. Se trata del registro del equipaje y víveres necesarios de religiosos franciscanos que se dirigen hacia su destino misional. Se registran: "veinticuatro baúles, cuatro petacas, una arca con avíos y demás ropas de vestir, arreos de montar y libros; un cajón con jícaras, vasos, platillos y chocolateras; tres arcas con Botica, libros de Devoción y ropa de [ilegible]; dos dichas con yerba, chocolate y azúcar; otra dicha con veinticinco escopetas; una bizcochera; cinco barriles de aguardiente y vino de la tierra; tres fardos con pan; tres barriles de escabeche; dos quintales de bacalao; seis arrobas de arroz; cuatro de garbanzos; fruta seca y batería de cocina, que nada adeuda mediante ser equipaje.” Archivo General de la Nación, Argentina (en adelante AGN), XIII-14-9-1, fo 104, partida 2.943 del 20-10-1779. Se podría intentar rastrear cada uno de los envíos aislados en dirección de Norte u otras agrupaciones espaciales, pero ello exige un trabajo que excede las posibilidades actuales. En este caso se lo hizo, y se pudo llegar al origen del movimiento de estos religiosos. Se trata de 22 franciscanos y de 5 laicos que los sirven, embarcados en la fragata 'San Pedro Regalado' poco después del 3 de diciembre de 1778 que es la fecha de la licencia que lo permitió. Archivo General de Indias, Contratación 5224, N.1, R. 102, Relación de pasajeros a Buenos Aires.
} 
el Alto Perú. Salta-Jujuy es el espacio de frontera entre el mundo andino y el de la planicie (todo es tierra baja visto desde el Altiplano), pero en muchos aspectos es más una 'provincia de arriba' que de 'abajo'. Ya el traslado de la aduana seca de Córdoba (creada en $1622^{40}$ ) a Jujuy en 1695 muestra dónde estaba el nodo que había que controlar en los tratos entre el Alto Perú y los circuitos del sur. Como se resalta siempre, hasta allí llegan las carretas y desde ese punto la mula es imperativa. Todos los que quieren ir al Alto Perú, deben pasar por allí. En el espacio salto-jujeño se entrelazan las ondas expansivas que llegan del Atlántico y las que se generan en los distritos mineros, que por la geografía y el estado de la tecnología opera como un complejo portuario seco.

El gran tema en Norte es el impacto de las rebeliones de 1780-1781 en la "región nodal para el comercio de «efectos de Castilla». Es decir, el Alto Perú". A partir de correspondencia mercantil Juan Carlos Garavaglia registra que "desde 1780 y hasta 1782 , se suceden las interrupciones del tráfico, los cortes de caminos, los saqueos, etc., que dificultaron y, en algunos casos, imposibilitaron el libre acceso de los comerciantes ligados al área porteña a los ricos mercados altoperuanos." ${ }^{41}$

Ello podría verse reflejado en las curvas correspondientes a este circuito, que cuenta con menos envíos pero con más cantidades de registros de bienes, lo que a su vez puede estar mostrando una reducción del número de participantes. Pero en líneas generales las curvas siguen el mismo ritmo que las demás, cuando se esperaba encontrar una seria crisis y hasta un descalabro- de la circulación, ya que llega hasta el propio escenario de las rebeliones. Sin embargo, los negocios siguieron su curso y tal vez eso ya da indicios de quiénes consumen los bienes transados.

Se registran para Centro 3,98\% del total de notas o 14,12\% de las interregionales (Tabla 4). Se incluye la mitad de los envíos a la ciudad de Córdoba y todos los correspondientes Santiago del Estero, Tucumán, Catamarca y La Rioja, así como a sus espacios jurisdiccionales. Ya se mencionó la función redistribuidora de la ciudad de Córdoba, hacia dentro de su jurisdicción, hacia otros espacios del Tucumán y hacia el Alto Perú. También son fenómenos presentes en San Miguel de Tucumán y Santiago del Estero. Los envíos a Catamarca y La Rioja seguramente eran para el consumo local y son interesantes porque muestran ambas ciudades en cierto modo escapando a la órbita de Córdoba, que era su

${ }_{40}^{0}$ Decisión tomada al mismo tiempo que se crea la Carrera de Buenos Aires, es decir, la navegación en dirección del río de la Plata por medio de registros sueltos cuyos bienes se podrían comercializar en las gobernaciones de Tucumán, Buenos Aires y Paraguay.

${ }^{41}$ J. C. Garavaglia, "El Río de la Plata en sus relaciones atlánticas”, p. 69. 
Fernando Jumar

principal proveedora y compradora de sus escasos excedentes. Algo que resulta curioso es que si se comparan los datos de Centro con los de Norte, tras la caída de 1781 Norte se recupera más rápido, lo que invita a pensar en más explicaciones para los movimientos que la provista por el efecto tenaza sobre los circuitos de las rebeliones altoperuanas y la guerra atlántica.

Los gráficos 2 a 5 muestran desagregadas las tendencias de la circulación extra-regional. Si se observan los correspondientes a Centro (Gráfico 2) y Norte (Gráfico 3), sea lo que sea que haya pasado en el medio, entre 1779 y 1783 algo ha cambiado porque al parecer Centro experimenta alguna dificultad y Norte crece considerablemente en intensidad y densidad de tratos directos con Río de la Plata. Si naturalmente el impacto de las rebeliones de 1780-1781 (visibles en 1781-1782) fue mayor en Norte, se recupera mucho más rápido que Centro.

Claramente el comercio que opera desde Buenos Aires se está lanzando a la conquista del Alto Perú. Las cifras desagregadas de este espacio (Tabla 5, al final del texto), muestran que mayormente ese comercio tiene fuerza para llegar hasta Salta-Jujuy. Inclusive cuando los caminos del Alto Perú eran nuevamente seguros se ve que la mayor intensidad y densidad de tratos directos de Buenos Aires es con Salta-Jujuy. Allí, los altoperuanos toman el control y son mayormente responsables de la comercialización en su espacio.
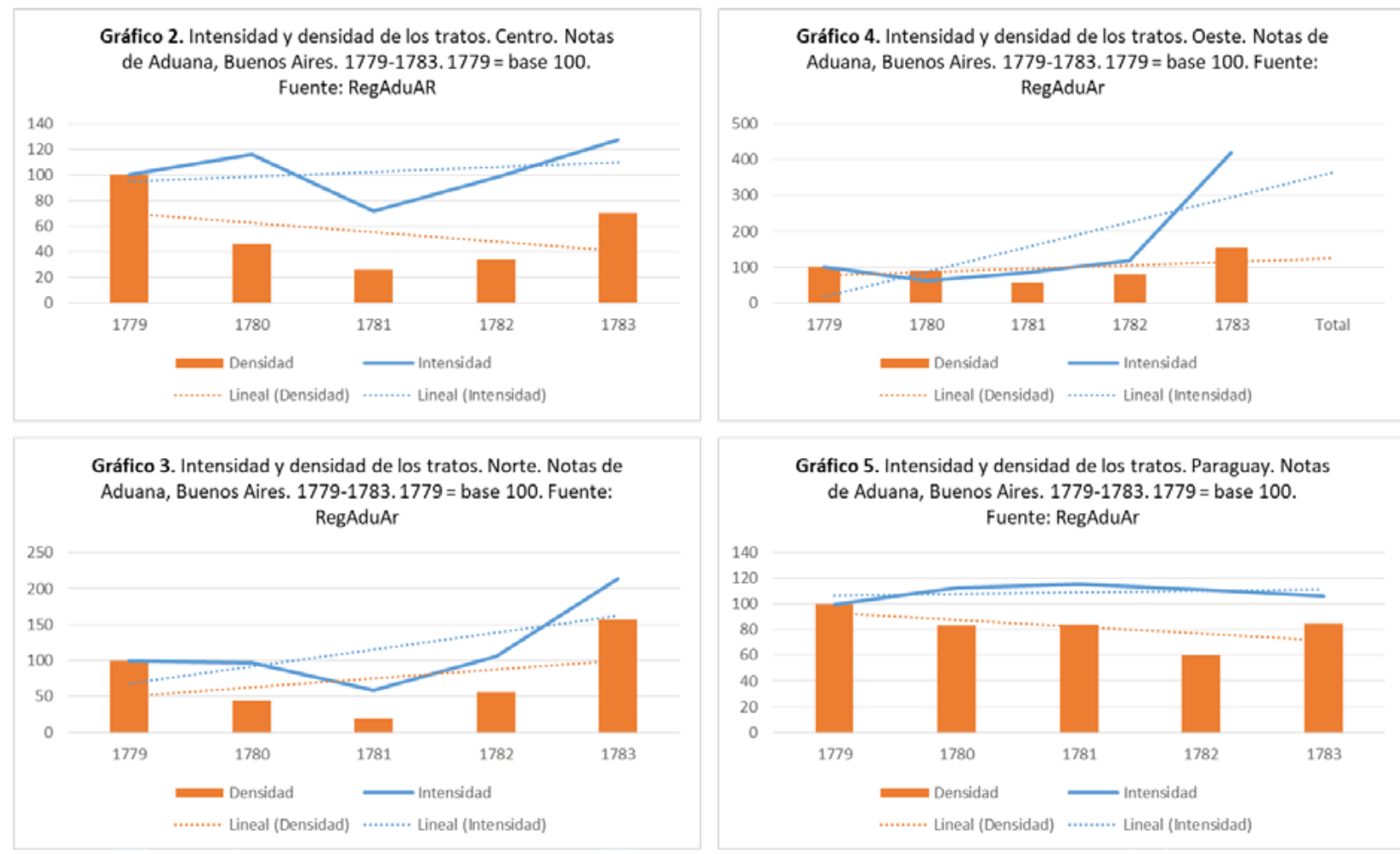
Lo que más llama la atención en la Tabla 4 es que invita a otorgar a Oeste el lugar que le daba al Alto Perú.

El Gráfico 4 señala es que los movimientos hacia Oeste dependen sobre todo de lo que pasa en el Atlántico y que la guerra de 1779-1783 no parece haber causado estragos, elemento señalado por Maximiliano Camarda. Afecta el volumen de lo transado, pero al mismo tiempo aumentan los contactos reforzando la integración. Recibe 46,61\% de las notas interregionales y 13,15\% de las totales, mientras que en densidad, se remiten allí $33,73 \%$ de los registros de bienes extra-regionales o $14,38 \%$ del total.

José Sovarzo analiza esta ruta en particular. Ve en Mendoza la "garganta del comercio" hacia Chile y el Pacífico, seguida por San Juan. San Luis se presenta ante él más cerca de Centro que de los circuitos tras-cordilleranos. María Claudia Errecart en su análisis de los caminos y los transportes, también señala la fuerza de este circuito, por lo demás ya conocida por el trabajo de Samuel Amaral sobre la circulación de caldos vista desde las cajas cuyanas en el período $1780-1820^{42}$ y más tarde por el de Silvia Palomeque, que amplía la mirada a toda la circulación de las tres ciudades y las inserta en los que son sus circuitos extra-regionales entre 1800 y 1810.43

La distribución de bebidas alcohólicas desde Buenos Aires confirma todo lo conocido sobre las interdependencias entre Cuyo y Río de la Plata. Dejando de lado algunas bebidas alcohólicas ${ }^{44}$ para centrar la observación en el vino y el aguardiente, el Gráfico 6 confirma claramente el predominio de la producción americana. En la Tabla 6 los envíos de vino y aguardiente americanos hacia Oeste requerirán alguna explicación (¿Devoluciones?). Los productos españoles no son competencia y sostienen las apreciaciones de Amaral. También se observa que lógicamente, si Centro y Norte consumen alcoholes americanos en cantidad no llegan por Buenos Aires de modo mayoritario. Lo que tal vez haya que explicar son los barriles que sí lo hacen por esa vía ya que revelan un circuito triangular en principio innecesario, si es que se trata de caldos cuyanos.

\footnotetext{
${ }^{42}$ Samuel Amaral, “Comercio libre y economías regionales. San Juan y Mendoza, 1780-1820”, en Jahrbuch für Geschichte von Staat, Wirtschaft und Gesellschaft Lateinamerikas, 27, 1990, pp. 1-67.

${ }^{43}$ S. Palomeque, "Circuitos mercantiles".

44 Cerveza, diversos licores, destilados de caña, sidra, rosolis (un aguardiente aromatizado con canela, azúcar y otros ingredientes), mistela (mezcla de vino, azúcar y canela) y tintilla (aún no se ha podido identificar con precisión, la voz aparece por primera vez en el Diccionario de la Real Academia en su edición de 1884, "vino, astringente y dulce, que se hace en la villa de Rota”, http://ntlle.rae.es/ntlle/SrvltGUILoginNtlle [consulta 05/03/2019]).
} 


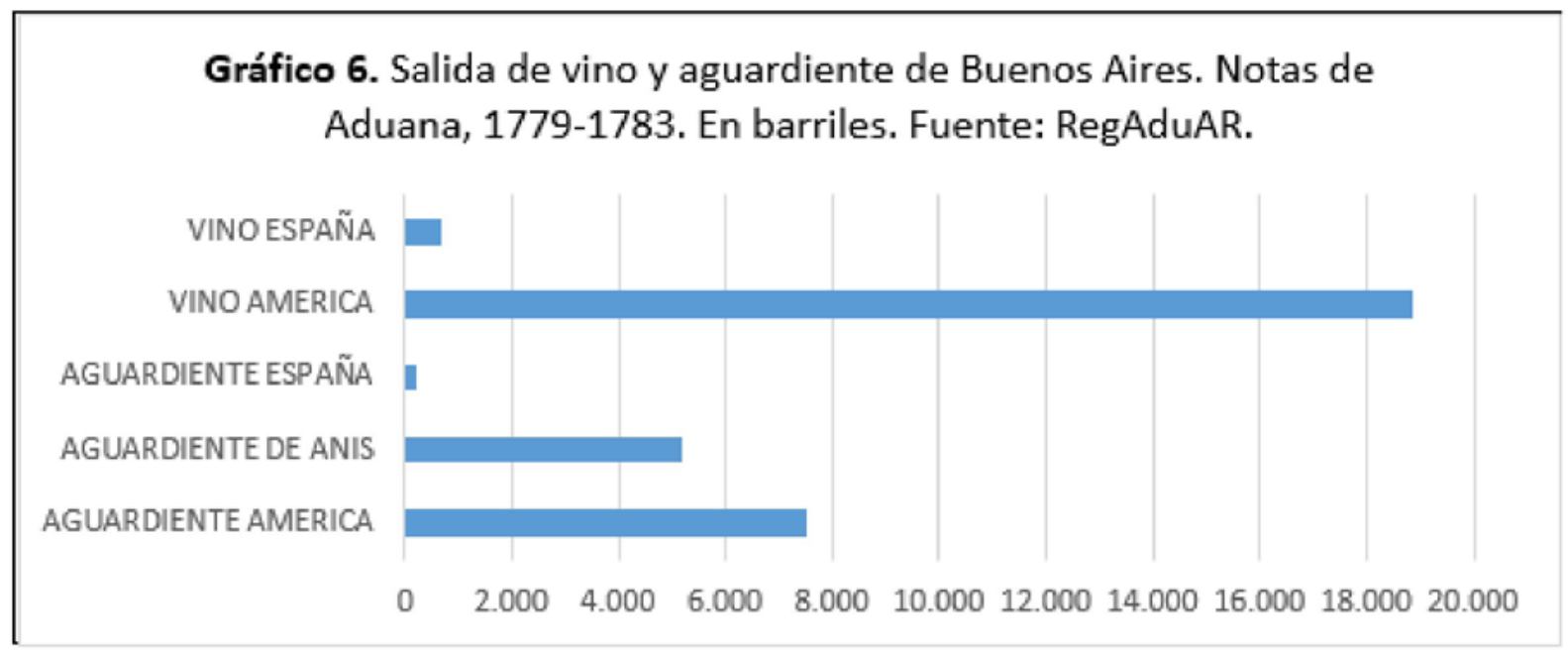

Tabla 6. Distribución de vino y aguardiente. Notas de Aduana. Aduana de Buenos Aires. 1779-1783. En barriles

\begin{tabular}{|lr|r|r|r|r|}
\cline { 2 - 6 } \multicolumn{1}{c|}{} & \multicolumn{1}{c}{ Centro } & \multicolumn{1}{c}{ Norte } & \multicolumn{1}{c}{ Oeste } & \multicolumn{1}{c|}{ Paraguay } & \multicolumn{1}{c|}{ RdIP } \\
\hline Vino Aca. & 87,13 & 67,07 & 10,34 & 663,89 & $18.042,93$ \\
\hline Vino Esp. & 25,19 & 36,00 & 4,00 & 22,13 & 583,09 \\
\hline Agte. Aca. & 19,52 & 7,00 & 5,00 & 3,00 & $7.493,12$ \\
\hline Agte. Esp. & 12,25 & 3,00 & 1,00 & & 220,00 \\
\hline Agte. anisado & & & & 0,44 & $5.174,69$ \\
\hline Total & 144,09 & 113,07 & 20,34 & 689,46 & $31.513,83$ \\
\hline
\end{tabular}

Fuente: RegAduAR.

Si se observan los envíos a Paraguay, apenas se remite aguardiente. Intuyo que preferían la cachaça que podía llegar de mil modos en esas fronteras con el mundo portugués. Si el consumo de vino y aguardiente podría ser un modo en el que la economía paraguaya dinamiza las economías cuyanas, no es nada frente a lo que esas economías hacen por la suya con la función redistribuidora de la yerba hacia el Pacífico.

Ciertamente, lo más interesante de esta tabla es la cantidad de barriles que aparentemente se consumen en la región Río de la Plata. No están revelando una población fija que pasaba sus días en estado de ebriedad, sino la provisión de las dietas diarias reglamentarias de los navíos del comercio y del servicio real para las continuaciones de sus viajes, elemento que analiza María Emilia Sandrín para ponderar variables que dinamizan la economía regional al tiempo que revela un mundo del trabajo hasta ahora poco conocido. Atraen los barriles de aguardiente de anís porque algunos indicios invitan a pensar que se 
en parte tal vez se prepare en la región Río de la Plata ${ }^{45}$ y se consumen en su espacio regional o se embarcan. Despierta curiosidad un consumo tan localizado.

En cuanto a las notas registradas en dirección de Paraguay, en intensidad suman $18,48 \%$ de los contactos extra-regionales o 5,21\% de los totales, mientras que en densidad, se lleva 20,3\% de los registros de bienes a nivel extra-regional u 8,66\% del total.

Como en los otros casos y como ya había señalado Isabel Paredes ${ }^{46}$ y refuerza Maximiliano Acebal47, ambos observando desde la caja asuncena, Asunción además de atender su consumo es el nodo integrador de los circuitos de su propio espacio. A través de sus trabajos, que analizan la caja asuncena con las mismas fuentes que se trabajaron para la de Buenos Aires, entrevén a través de la circulación lo que puede ser el adentro y el afuera paraguayo. Entre otras cosas que llaman la atención se ve a Corrientes con un comportamiento errático, que pivotea entre la atracción de Buenos Aires y la de Asunción. Complementando lo que se observa desde Buenos Aires, también ve que una parte de los pueblos de las Misiones cae en el campo de atracción asunceno, mientras que desde Buenos Aires se ve caer bajo su influjo a otros. Requiere explicación que la frecuencia de contactos esté al nivel de las de Centro y Norte, cuando la bibliografía invita a pensar en una sociedad desmonetizada con escasa o nula inserción en el comercio, a no ser por la exportación de yerba mate.

Finalmente, el Gráfico 5 muestra que la ruta de Paraguay tiene sus propias lógicas y que poco la afecta lo que esté pasando en el mundo. Mientras Río de la Plata demande sus producciones. En la medida en que se pueden cruzar datos entre lo que sale y lo que entra de Paraguay en función de bienes y sus cantidades, se intuye que cuando se les asigne valor la balanza comercial será positiva para Asunción.

Entre lo que llega de Paraguay se destaca como es sabido la yerba mate. Desde Buenos Aires se redistribuyen 496.620,62 @ de yerba en todas direcciones. Ignorando ahora34@ enviadas a Paraguay (seguramente devoluciones), el Gráfico 7 presenta la distribución restante (496.586,62@).

\footnotetext{
${ }^{45}$ Salen de Buenos Aires 279,5@ de anís; 48,7\% hacia Centro (2,5\%), Oeste (10,02\%), Paraguay (36,18\%) y 51,3\% dentro de Río de la Plata.

${ }^{46}$ Isabel Paredes, "La carrera del Paraguay a fines del siglo XVIII", en América Latina en la Historia Económica, 21, 1, 2014, pp. 66-91; "El comercio de la subregión de Paraguay a fines del siglo XVIII", en XIII Jornadas Interescuelas/departamentos de Historia, Universidad Nacional del Comahue, San Carlos de Bariloche, 2009, http://cdsa.aacademica. org/ooo-008/610.pdf (consulta 10/02/2019); "Los transportistas asuncenos de la Carrera del Paraguay y sus relaciones comerciales con Buenos Aires”, en XIV Jornadas Interescuelas/Departamentos de Historia, Universidad Nacional de Cuyo, Mendoza, 2013, https://www.aacademica.org/ooo-010/264 (consulta 10/02/2019).

47 Maximiliano Acebal, “Caminos del río Paraguay: Asunción y sus áreas de influencia económica, 1779-1783”, en 6tas. Jornadas de Historia Económica, Asociación Uruguaya de Historia Económica, Montevideo, 2-4 de diciembre de 2015.
} 
No se tienen datos de la yerba que se distribuía por otros circuitos, pero el consenso historiográfico es que la mayor parte se redistribuía desde Buenos Aires. Si es así, las curvas invitan a pensar que a través de Río de la Plata la economía paraguaya está orientada hacia el Pacífico y que el segundo consumidor de su apreciado bien es Río de la Plata. Pero son datos posiblemente engañosos, ya que Centro y Norte podrían seguir siendo abastecidos desde Santa Fe por más que pierda su condición de puerto preciso en el trajín entre Asunción y los puertos rioplatenses. A menos que el mate no haya sido popular en esos espacios, sobre todo en Norte.

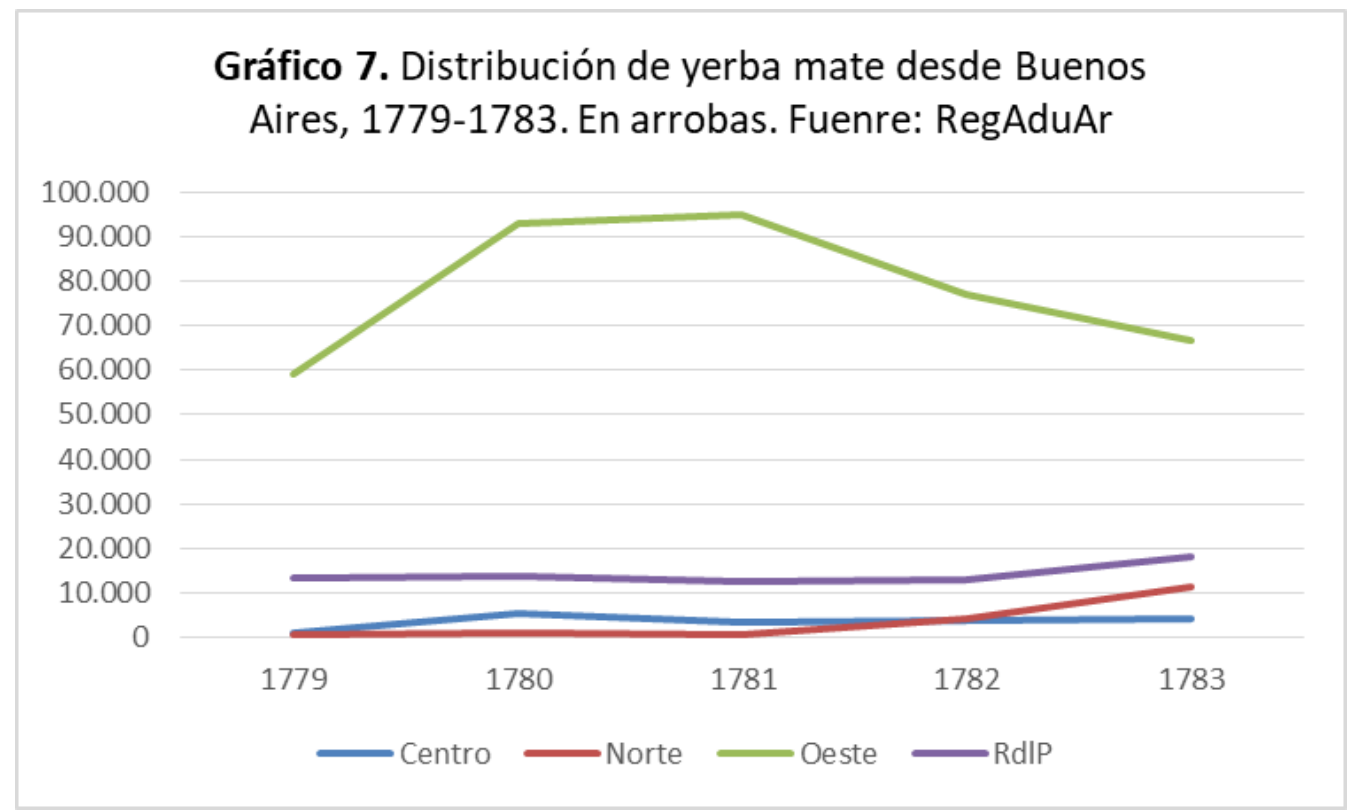

En síntesis, la circulación extra-regional rioplatense muestra que más allá de la doble perturbación que afecta la circulación en el período observado, Buenos Aires tiene circuitos bien amarrados, que reaccionan de modo diverso ante la coyuntura sin verse seriamente afectados y que en conjunto mantienen un alto nivel de transacciones. Oeste y Paraguay son los que más atraen por las complementariedades observadas a partir del papel de Río de la Plata en la redistribución y/o consumo de sus propias producciones regionales. Centro y Norte parecen menos volcados al puerto y ello tal vez se explique por los contactos de Córdoba con el Pacífico a través de Mendoza-San Juan y del Alto con el Bajo Perú.

La visión de conjunto invita a pensar que los metales preciosos que se observan saliendo de Buenos Aires (Tabla 7$)^{48}$ no llegaron de modo dominante desde los circuitos

\footnotetext{
${ }^{48}$ Las cifras de la Tabla 7 no son las de las salidas de metales preciosos en dirección a Europa, sino sólo las que se remiten de Buenos Aires hacia otros espacios. Se trata de la usual diversidad de metales amonedados, en pasta y labrados, reducidos a pesos de 8 reales.
} 
del Centro y del Norte a través del comercio. El oro sin dudas llegó desde Chile y por el volumen de negocios con ese rumbo buena parte de la plata también. Además, no todos esos metales están circulando como retornos del comercio ultramarino.

No sorprende que la mayor parte se distribuya dentro de la región. Se registran para Montevideo 12.456.245,12 pesos. Los 385.869,01 pesos restantes revelan alguna parte de lo que Buenos Aires está pagando a sus proveedores regionales o por servicios. También muestran inversiones relacionadas con establecimientos productivos y pagos de salarios. ${ }^{49}$ Es más que lo que sale de Buenos Aires hacia la circulación extra-regional,

237.055 pesos. De ellos, Paraguay recibe 73,03\% y Oeste le sigue, de lejos, con $18,78 \%$. No se puede decir mucho más ahora porque sería necesario separar entre los caudales del rey, de Dios y de los hombres, y luego considerar los motivos por los que son puestos en movimiento, cuando se puede saber, lo que merece un análisis particular.

Tabla 7. Salidas de metales preciosos, notas de aduana, Aduana de Buenos Aires, 1779-1783

\begin{tabular}{|l|r|}
\cline { 2 - 2 } \multicolumn{1}{c|}{} & Pesos de a 8 \\
\hline 01. Centro & 11.648 \\
\hline 02. Norte & 7.766 \\
\hline 03. Oeste & 44.517 \\
\hline 04. Paraguay & 173.124 \\
\hline 05. RdIP & 12.605 .059 \\
\hline Total & 12.842 .114 \\
\hline
\end{tabular}

Fuente: RegAduAR

La imagen general es que se está ante economías que atraviesan una moderada prosperidad o privilegian para el gasto de sus presupuestos el consumo de bienes tenidos por suntuarios por la bibliografía, cuando se trata de efectos de Castilla. Acomodándose a alguna perturbación, es lo normal, pero recuperándose con rapidez. Hay perturbaciones, no crisis. En alguna medida esas economías deben su moderada prosperidad a sus

${ }_{49} \mathrm{En} \mathrm{8,26 \%} \mathrm{de} \mathrm{los} \mathrm{registros} \mathrm{que} \mathrm{contienen} \mathrm{metales} \mathrm{preciosos} \mathrm{la} \mathrm{fuente} \mathrm{contiene} \mathrm{excesos} \mathrm{de} \mathrm{información} \mathrm{que} \mathrm{permite}$ saber el motivo porque son puestos en movimiento. 
Fernando Jumar

articulaciones con Río de la Plata y su complejo portuario ya que Buenos Aires no sólo envía hacia allí los más diversos bienes, sino también porque consume o redistribuye sus propias producciones..$^{50}$

\section{La circulación intrarregional}

Como ya se mencionó, la fuente trabajada no permite ver lo consumido en Buenos Aires, ni se han trabajado las notas de Montevideo o de las receptorías menores que completarían el cuadro de la circulación intrarregional. De modo que las cifras que se presentan ahora sin dudas dan una versión pobre de la circulación en la banda norte del río que se abastecía directamente en Montevideo y del consumo en la ciudad sólo se ve lo que llega de Buenos Aires. Los datos disponibles ahora se estiman sólo suficientes para delinear los contornos regionales y señalar tendencias (V. Mapa 2, al final del texto). Si en la circulación extra-regional sólo se ven los ejes principales de la circulación, en la intrarregional se observa la redistribución interna desde una de las cabezas de un espacio que tiene dos en el momento observado (Buenos Aires y Montevideo) y que hasta hacía muy poco tenía tres (se sumaba Colonia del Sacramento bajo dominio portugués).

Para esta época, Buenos Aires, como la caracteriza T. Halperin Donghi no pasa de ser una ciudad española de segundo orden ${ }^{51}$ y sin dudas es la menos opulenta de todas las capitales virreinales. Lamentablemente no la vemos en su consumo en este texto, pero por las producciones americanas que salen de allí hacia otros destinos (americanos y extra-americanos) y las que consume y transforma para asegurar sus funciones de cabeza del complejo portuario y sede de los poderes monárquicos superiores ${ }^{52}$, es un mercado atrayente para las economías del interior americano. Montevideo está en plena ebullición a fines del siglo XVIII. Una parte de los envíos que se hacen desde Buenos Aires son materiales de construcción (maderas, cerramientos, herrería de obra, cerrajería). El ritmo de crecimiento acelerado se observa en la ausencia o insuficiencia de ciertos oficios; por

\footnotetext{
${ }^{50}$ Que no se limitan a los caldos cuyanos y la yerba paraguaya. También hay textiles. Por ejemplo, 66.624 ponchos, entre los que se pueden identificar 14.975 que habían llegado a la capital desde Córdoba y 383 de Santiago del Estero. También, 126.163,5 varas de diversos textiles de la tierra, 5.390 registros de derivados animales y seguramente la mayor parte de lo contenido en 1.505 registros de bienes que contienen materiales de construcción y reparaciones, 20.559 de alimentos o en 3.781 de talabartería y aperos de montar, entre otras categorías de bienes en los que se ha detectado producción americana, que va ganando espacio en las especulaciones frente a la imagen previa que tenía en la que dominaban ampliamente los efectos de Castilla.

${ }^{11}$ T. Halperin Donghi, Revolución y guerra, p. 50.

${ }^{52}$ V. el trabajo de María Emilia Sandrín en este dossier.
} 
ejemplo, parece que no hay quien haga buenas sillas ${ }^{53} \mathrm{y}$ los talabarteros que haya no dan abasto ${ }^{54}$. Colonia del Sacramento, al comenzar el período analizado, acaba de entrar en el largo letargo del que sólo la sacará su declaración como Patrimonio de la Humanidad en 1980. Ya no cumple funciones articuladoras con espacios extra-americanos y pasa a ser uno más de los puertos que integran la región hacia adentro.

Las políticas de colonización interna que lleva adelante la Corona en el conjunto de sus dominios también se observan en Río de la Plata, lo que se traduce en muchos nuevos asentamientos en las campañas, en lo que Julio Djenderedjian llamó la “Arcadia criolla”, en las bandas norte y sur del Río de la Plata y la aventura mayor que se emprende en dirección de las costas e islas del Atlántico sur. Ello es visible en la dispersión regional de los envíos que acompañan el crecimiento de la población rioplatense.

\title{
A nivel intrarregional, la circulación registrada en Buenos Aires muestra:
}
a) el aprovisionamiento de comercios minoristas ${ }^{56}$;
b) consumo directo 57 ;
c) aprovisionamiento de unidades productivas ${ }^{8}$;

\begin{abstract}
${ }^{53}$ Entre 1779 y 1783 salen de Buenos Aires 5.457 sillas de diversas calidades (pero la mayoría parecen ser de las más simples por la ausencia de descripciones que revelen calidades superiores). La circulación interregional se lleva 875 unidades (287 hacia Centro, 486 hacia Norte, 83 hacia Oeste y 19 hacia Paraguay); la intrarregional 4.582 unidades para la intrarregional) De ellas, 3.827 se enviaron a Montevideo (1.403 unidades con declarado fin mercantil. RegAduAR.

${ }^{54}$ Hay 3.781 registros de bienes entre 1779 y 1783 en la categoría 'talabartería y aperos'. Las regiones interiores suman 529 registros de bienes y 3.252 para dentro de la región, de las que 2.221 de despachan a Montevideo. Las últimas contienen: 31 pares de alforjas; 3.270 argollas de lazo; 192 barbiquejos; 1 baticola, 42 caronas de lana; 789 caronas de suela; 83 cabezadas; 28 chapeados; 152 cinchas de cuero; 45 cinchas de lana; 1.727 cojinillos; 160 correas; 6.060 pares de espuelas; 20 de lazos; 1.487 de estribos; 5.979 de frenos; 4.190 lomillos; 480 monturas; 3.402 pellones; 1.500 plumas; 7 pretales; 2.535 riendas; 52 sobrecinchas; 20 sudaderos, 4 sunchos, y la estrella del lote, 14.646 vainas de cuchillo. RegAduAR.

55 Julio Djenderedjian, "Economía y sociedad en la Arcadia criolla. Formación y desarrollo de una sociedad de frontera en Entre Ríos, 1750-1820”, Tesis de Doctorado inédita, Universidad de Buenos Aires, 2003.

${ }^{56}$ Un lote "típico" se compone de vino y aguardiente (uno o dos barriles de cada uno), yerba, azúcar y algunos textiles (en pocas cantidades). Alrededor aparece todo tipo de bienes, pero siempre en pocas cantidades y de modo ocasional, como si se estuviese satisfaciendo pedidos puntuales.

${ }^{57}$ Entre las tantas cosas que revela esta fuente se observa un inesperado grado de cumplimiento de ciertas normas por parte de la población cuando no había casi ninguna capacidad de hacerlas cumplir o de reprimir su incumplimiento por parte de las autoridades. Ello se ve a través de las personas que eligen cumplir con las disposiciones que establecían que debían ser declarados en la Aduana hasta los bienes de uso personal que se llevaban con motivo de desplazamientos. Invariablemente, entre lo declarado aparecen víveres para el viaje o compras realizadas en Buenos Aires para el consumo propio y familiar (textiles, por ejemplo). También revelan consumo directo envíos realizados desde Buenos Aires que corresponden a encargos puntuales realizados desde otros puntos de bienes para el consumo personal y familiar de personas que no se desplazan a Buenos Aires pero que están insertadas en alguna red relacional que cuenta con un comerciante asentado en la capital, dispuesto a hacer el favor.

${ }^{5}$ Alimentos y herramientas sobre todo para estancias, caleras y aserraderos. Como se mencionó, la fuente contiene a veces excesos de información que permiten adentrarse en el destino de lo enviado. Es así que se pudo ver que al menos 103 notas fueron registradas con bienes para diversos fines en estancias de los declarantes que usualmente los remiten por mano de terceros. Otras veces, aunque nada se especifique, es evidente que se está ante insumos productivos. Como
\end{abstract}


d) insumos para el ejercicio de oficios ${ }^{59}$;

e) la provisión de bienes y servicios a la navegación mercantil y militar ${ }^{60}$;

f) ecos del comercio ultramarino ${ }^{61}$;

g) la provisión de bienes y servicios para la administración y la defensa;

h) la provisión de bienes y servicios para la colonización en el Atlántico sur, así como en Entre Ríos y la banda norte.

No es objeto de este texto abordar el análisis de los bienes puestos en circulación, pero conviene tener lo señalado en consideración a la hora de ponderar las cifras que se presentan.

Tabla 8. Circulación intrarregional rioplatense

\begin{tabular}{|l|r|r|}
\cline { 2 - 3 } \multicolumn{1}{c|}{} & Intensidad & Densidad \\
\hline Banda norte & 780 & 5.224 \\
\hline Banda sur & 672 & 5.432 \\
\hline Complejo portuario & 9.645 & 40.104 \\
\hline Litoral & 1.316 & 13.239 \\
\hline Atlántico sur & 66 & 695 \\
\hline Total & 12.479 & 64.694 \\
\hline
\end{tabular}

Fuente: RegAduAR.

La Tabla 8 presenta en detalle los envíos registrados. La información fue organizada teniendo en cuenta los contactos entre los puntos del complejo portuario rioplatense, hacia el interior de la banda de Buenos Aires, de la banda norte, el litoral (los espacios ríos Paraná y Uruguay arriba incluidos parte de los pueblos de las misiones) y de las islas y costas del Atlántico sur ${ }^{62}$.

por ejemplo, la cuchillería que también ilustra sobre las deficiencias de los datos actuales ante la carencia de los de Montevideo. Salen de Buenos Aires 736.019 unidades de cuchillería de distinto tipo. Río de la Plata recibe sólo 15,43\%, cuando se esperaba ver ese tipo de bienes circulando de modo mayoritario a nivel intrarregional, por su asociación a las labores del cuero. Este puede ser un ejemplo concreto de las distorsiones esperadas por la ausencia de las notas de Montevideo, ya que lo predecible sería que la producción ganadera que opera en la banda norte se aprovisiones al menos en parte allí, que es además donde se desembarcaban, si es que no se producían localmente. RegAduAR.

${ }^{59}$ Se ponen en circulación, muchas veces en manos de sus dueños, herramientas e insumos para tareas de afilador, armero, barbero, carpintero, albañil, costurera y sastre, destilador, panadero, herrero, orfebre, tejedor, tornero, zapatero, etc.

6o Todo lo que se pueda imaginar relacionado con las estadías de marineros y soldados así como el mantenimiento de las embarcaciones.

${ }^{61}$ Sobre todo a través de envíos a Montevideo de metales preciosos y derivados animales que sin dudas en su enorme mayoría se remitían a Europa.

${ }^{62}$ Se los considera parte de la región Río de la Plata ya que los intentos de colonización y/o el manejo de los puestos militares se hacen desde ella, que también tiene la responsabilidad del abastecimiento en todo tipo de bienes (principalmente los destinados a la supervivencia de colonos y soldados). 
Desagregados los datos, Tabla 9 (al final del texto), lo primero que señalan es que en los contactos entre los componentes del complejo portuario (9.645 notas con 40.104 registros) Montevideo se lleva la parte del león (7.462 notas con 30.379 registros de bienes), pero si se aíslan sus envíos la circulación intrarregional rioplatense sigue siendo la predominante en el conjunto. Montevideo no consume todo lo que se le envía, sino que a su vez redistribuye hacia su traspaís y antepaís.

Los envíos al Atlántico sur tienen su propia lógica que deriva de los esfuerzos colonizadores de la Monarquía. ${ }^{63}$ Esencialmente son envíos (66 notas con 695 registros de bienes) por cuenta de la Real Hacienda y/o de familiares de los servidores reales apostados en esos destinos ${ }^{64}$ con alimentos y vestuario en expediciones de reabastecimiento que se enviaban desde Montevideo. De esos embarques se ve lo que se remite desde Buenos Aires, a lo que se debe sumar lo registrado en la otra banda.

En general, la circulación dentro del complejo portuario se descompone en tres tipos básicos: circulación para el aprovisionamiento de la población fija y flotante sobre ambas bandas, para ser trasbordada a los navíos que abandonan el río y para empalmar -sobre todo en Las Conchas- con ríos arriba.

Los envíos sobre la banda sur (672 notas con 5.432 registros) comparten las características de los realizados a la banda norte (5.224 registros) y, dentro del litoral, con los agrupables (siguiendo toponimia actual) en Entre Ríos y sur de Santa Fe (4.760 registros de 13.239 para el sub-conjunto). Son los circuitos de la campaña rioplatense visibles desde Buenos Aires. Lo animan muchos actores mediante pequeños

\footnotetext{
${ }_{63} \mathrm{Al}$ respecto, interesan ahora trabajos que abordan temas presentes en este texto, como el consumo y las relaciones mercantiles con el mundo indígena. V. p. e. María Ximena Senatore, Arqueología e historia en la colonia española de Floridablanca. Patagonia, siglo XVIII, Buenos Aires, Editorial Teseo, 2007. Marcia Bianchi Villeli, "Organizar la diferencia: prácticas de consumo en Floridablanca", en Cuadernos del Sur, 35-36, 2007, pp. 375-406; Silvana Buscaglia, "Indígenas, Borbones y enclaves coloniales. Las relaciones interétnicas en el fuerte San José durante su primera década de funcionamiento (Chubut, 1779-1789)", en Corpus. Archivos virtuales de la alteridad americana, 5, 1, 2015, pp. 1-38; María Laura Casanueva, "Un poblado patagónico con identidad Castellano-Leonesa. Nuestra Señora del Carmen de Patagones, s. XVIII”, en Hernandarias. Revista del Instituto Argentina de Cultura Hispánica de Córdoba, 6, 4, 2014, pp. 33-69. Para los contornos generales del esfuerzo colonizador, v. Bruno Sancci, La colonización española en la Patagonia, Buenos Aires, De Los Cuatro Vientos, 2010.

${ }^{64}$ En particular la familia Viedma registra envíos a Francisco de Viedma que estaba al comando, exonerados del pago de derechos, y que por su cantidad despiertan alguna suspicacia sobre si además de consumir el servidor real no vendería remanentes.
} 
Fernando Jumar

y medianos lotes de bienes. Hay lotes de reaprovisionamiento de pulperías ${ }^{65}$ y lotes de consumo directo por parte de personas que se desplazan, regresando a sus moradas o moviéndose dentro de la región tal vez buscando trabajo. También hay registros que se declaran como insumos de explotaciones agrícolas, estancias, caleras o aserraderos, usualmente remitidos por sus propietarios aparentemente asentados en Buenos Aires por mano de terceros.

En el litoral también están las remisiones a Santa Fe (3.662 registros de bienes) y Corrientes (2.194 registros). La composición de los lotes es más compleja que los destinados a los espacios rurales, sobre todo en los textiles y diversos enseres de la vida cotidiana. Los envíos a los pueblos de las misiones, tanto los incluidos en la región Río de la Plata como en la de Paraguay, son vehiculizados de modo dominante por el Administrador de las Temporalidades radicado en Buenos Aires. Los pueblos recuperan en bienes de consumo e insumos parte del producto de la venta de lo enviado a Buenos Aires. Pero también se remiten por cuenta de esos pueblos, insumos para las faenas de ganado que sus habitantes están haciendo en las campañas de la banda norte, compitiendo con otros actores en la realización de vaquerías sobre las que pone el acento Nicolás Biangardi para sostener sus hipótesis en relación con la explotación corambrera.

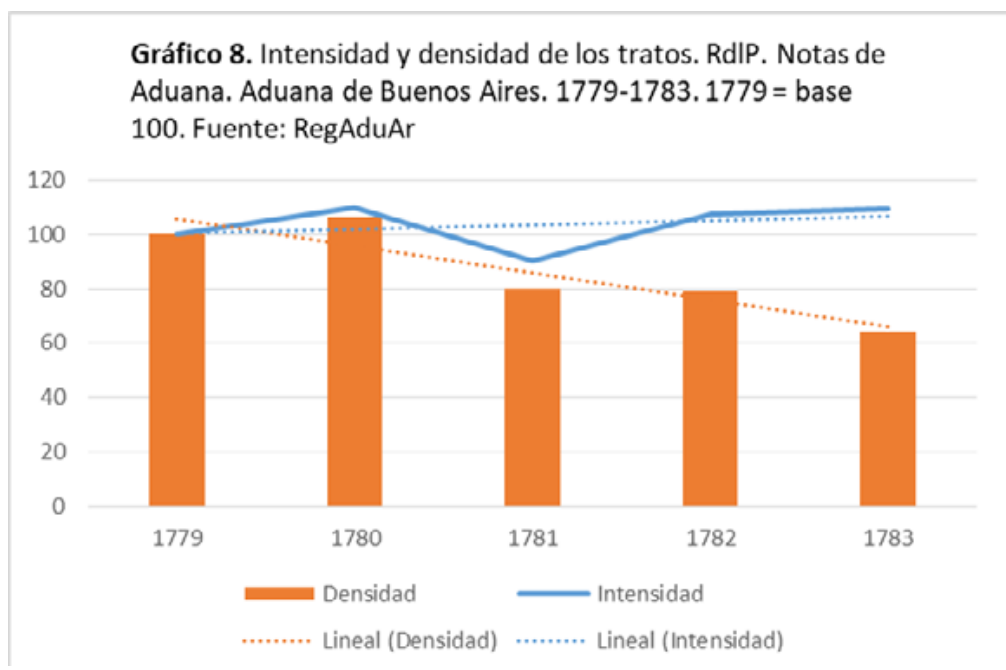

\footnotetext{
${ }^{65}$ Las pulperías tenían un sistema propio de pago de derechos para determinados bienes (la composición), con lo que es sencillo identificar las notas con ese destino, que usualmente contienen también bienes no incluidos en la tarificación especial. Así se identificaron 2.496 registros de bienes distribuidos en 31 categorías, entre las que sobresalen alimentación (1.143 registros), indumentaria (210), accesorios de indumentaria (126), mercería (162), telas al corte (314). Entre los 541 registros de bienes restantes lo único que remite claramente a actividades productivas de consideración es la cuchillería (68 registros). También se ve que hay quienes tejen (colorantes, algodón en rama, escarmenadores). Se escapan las notas destinadas a pulperías que no contenían los bienes sujetos a tarificación especial. Por ejemplo, se detectó un individuo, Cosme Espes, que durante todo el período realiza permanentes envíos de lotes compuestos por 1 barril de vino y otro de aguardiente como base, y algunas pocas cosas más (usualmente frutas disecadas y frutos secos). Tiene todo el aspecto de ser un proveedor especializado en las pulperías.
} 
El Grafico 8 muestra que se mantiene la intensidad por sobre las oscilaciones, pero la densidad baja. Los movimientos de ambas series muestran una dinámica que no se puede atribuir de modo particular a la coyuntura. Ello podría querer decir que los rioplatenses tienen menor capacidad de consumo y que las actividades económicas regionales decaen, o que se abastecen de otro modo. Sólo se podrá refinar la idea cuando se procesen los datos de Montevideo.

La circulación entre los puntos del complejo portuario rioplatense lo muestra en sus diversas funciones. Integración regional a través de envíos a los puertos menores que en algún grado se dispersan por la campaña circundante. Contacto de las economías americanas con las del resto del mundo sobre todo a través de los envíos a Montevideo, tanto de bienes para la exportación como para asegurar el funcionamiento portuario. Se observa un espacio regional integrado, con contactos más fluidos hacia determinados puntos, y muchos ocasionales. Los primeros tal vez muestren pequeños nodos redistribuidores en la campaña. Los segundos tal vez muestren personas que tuvieron que ir a la ciudad por algún motivo y se regresan con algunas compras y algún corte de angaripola para la patrona. También hay personas que se desplazan con sus herramientas para ejercer oficios o mujeres cargadas de hijos y enseres domésticos, que a veces declaran ir a reunirse con sus maridos.

Esos números, reorganizados en función de los envíos a Montevideo, Santa Fe, Corrientes, los pueblos de las misiones, y la campaña (banda sur, banda norte, Entre Ríos, sur de Santa Fe, los envíos a los puertos del complejo portuario rioplatense de circulación intrarregional) muestran comportamientos distintos.

La comparación entre Santa Fe y Corrientes muestra muy posiblemente el papel de la segunda en la articulación con Paraguay, lo que se condice con las observaciones hechas desde Asunción. En los datos para la campaña se teme que la ausencia de los de Montevideo esté deformando la observación, ya que las informaciones sobre producción y salidas de cueros aportados por Nicolás Biangardi y Maximiliano Camarda deberían reflejarse en un traspaís más consumidor y ello tendría que haber compensado el fin de los estímulos de la expedición de Cevallos en su papel demandante de bienes y servicios. 

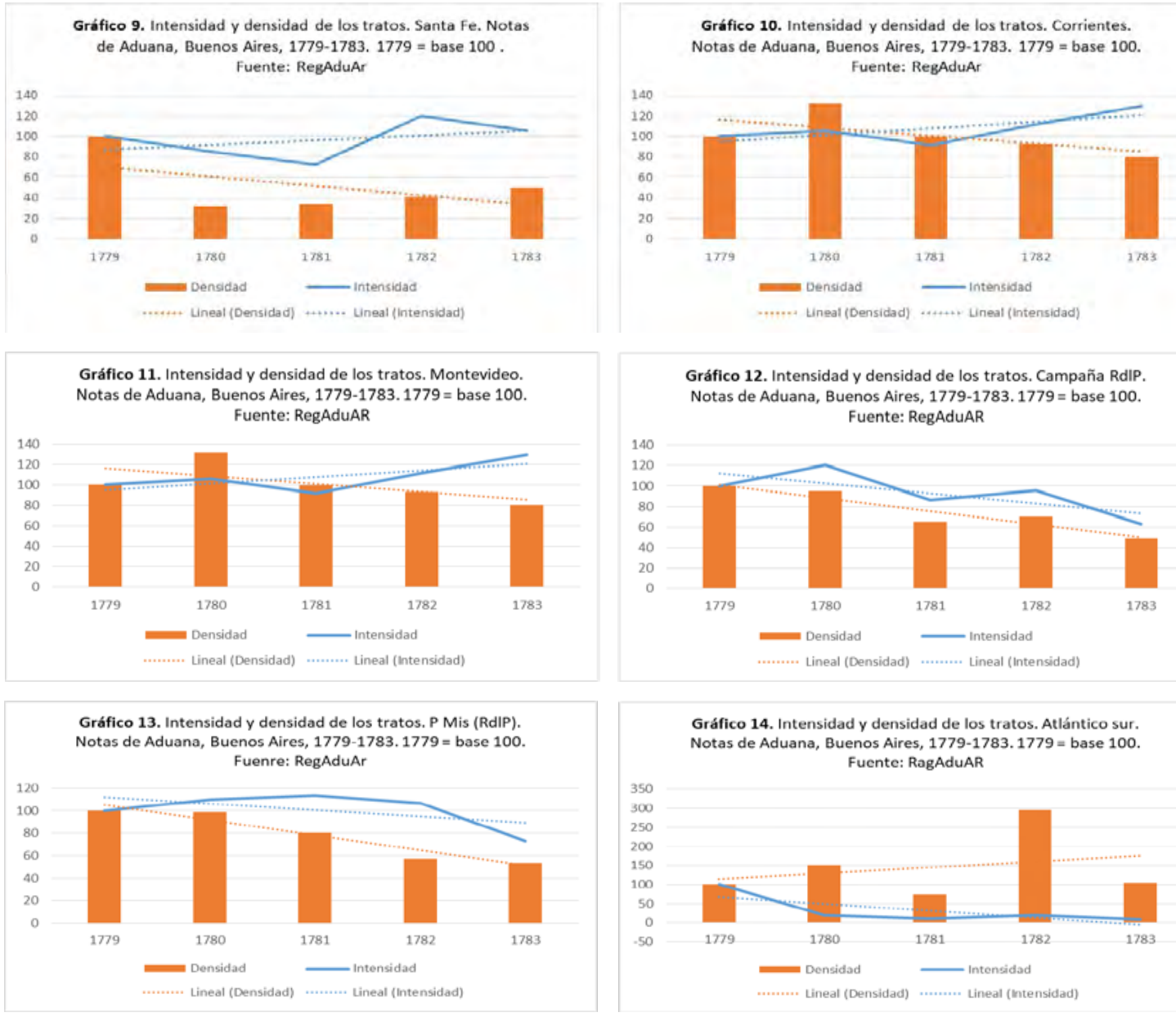

Gráfico 14. Intensidad y densidad de los tratos. Atlántico sur. Notas de Aduana, Buenos Aires, 1779-1783.1779 = base 100 . Fuente: RagAduAR

No sería prudente ir mucho más allá en la observación de la circulación intrarregional al faltar procesar la información de Montevideo. Los datos expuestos por ahora son utilizados como demostración de la dispersión y fluidez de los contactos entre ambas bandas y su dinámica integración.

\section{Conclusiones}

Los datos aportados en este trabajo se suman a otros, para períodos previos, contemporáneos y algo posteriores y que juntos buscan estudiar un espacio americano durante el Antiguo Régimen desde un punto de vista que se esfuerza por escapar a la fuerza gravitacional de los paradigmas nacional y colonial tanto como entroncar las explicaciones con las contenidas en las investigaciones generadas desde esos paradigmas.

El primer paso fue romper la espacialidad geonómica de las unidades analíticas para devolverles las que tenían en el tiempo a observar. De allí surge una concepción regional sin interferencias de fronteras nacionales ni de subdivisiones políticas dentro 
de las unidades soberanas tan laboriosamente construidas en el siglo XIX. La región Río de la Plata que veo emerger desde mis primeros trabajos de investigación se ajusta mal a otros "Río de la Plata" existentes en la historiografía, en cuanto a los espacios que se incluyen para ser analizados en tanto que unidad, la conformación de sus complejos productivos y de servicios, el comercio terrestre y fluvio-marítimo, diversos aspectos de la vida social y del mundo del poder.

Entre 2002 y 2016 varios investigadores vieron potencial en las ideas propuestas y aceptaron hacer propios temas de investigación que las sometían a prueba. Sin proponérnoslo llevamos adelante un programa de investigación que se tradujo en vinculaciones formales en proyectos acreditados ante diversos organismos y trabajos de posgrado -unos pocos de ellos aun en curso- que enriquecieron las ideas originales al tiempo que sustentan las hipótesis generales. Ya no estamos vinculados por proyectos de investigación dirigidos por mí, se ha cumplido un ciclo y esos investigadores comienzan sus propias aventuras intelectuales y de formación de recursos.

Del conjunto de ideas, expuestas en diversos trabajos, el presente buscó someter a prueba de modo concreto las hipótesis sobre las articulaciones espaciales de Río de la Plata en función de la circulación. El espacio económico rioplatense con su polo en la región Río de la Plata que en trabajos previos veía conformarse desde fines del siglo XVII aparece plenamente constituido al tiempo que se crea el Virreinato del Río de la Plata.

La región Río de la Plata desde comienzos del siglo XVIII inicia una etapa de crecimiento sostenido de su economía basada en la exportación de derivados bovinos ${ }^{66}$ y los diversos estímulos derivados de las demandas de bienes y servicios por el comercio y la Corona $^{67}$, que se refleja en una oligarquía comarcal madura e insertada con voz propia en el coro de voces que componen la Monarquía Hispánica ${ }^{68}$.

La atracción que ejerce el Atlántico a través de Río de la Plata así como la función de mediación que asume con el Pacífico la convierten tempranamente en cabeza de unos

\footnotetext{
${ }^{66}$ F. Jumar, "El primer boom de la exportación de cueros y la sociedad local. Río de la Plata. Fines del siglo XVII, comienzos del siglo XVIII, en Jornadas de Historia Económica, Asociación Argentina de Historia Económica/Universidad Nacional de Tres de Febrero, Caseros, 2008.

${ }^{67}$ Fernando Jumar; Nicolás Biangardi; José Bozzo; Sabrina Orlowski; Roberto Querzoli; María Emilia Sandrín, "El comercio ultramarino y la economía local en el complejo portuario rioplatense. Siglo XVIII”, en Anuario IEHS, 21, 2006, pp. 235-254.

${ }^{68}$ F. Jumar, "El precio de la fidelidad". La Guerra de Sucesión en el Río de la Plata, los intereses locales y el campo Borbón, en Annie Molinié; Alexandra Merle (Dirs.), L’Espagne et ses guerres. De la fin de la Reconquête aux guerres de l'Indépendance, París, Presses de l’Université paris/Sorbonne, 2004, pp. 203-236.
} 
Fernando Jumar

circuitos integrados, delimitados por tres complejos portuarios. Uno de agua, el rioplatense y dos secos, el salto-jujeño y el mendocino-sanjuanino. Es un conjunto de economías relativamente pequeñas que conforman un espacio económico polarizado hacia Río de la Plata visible desde comienzos del siglo XVIII y que articula relaciones con el Paraguay, el Alto Perú y, sobre todo, con Chile y a través de él con los puertos del Pacífico sur. El comercio ultramarino que opera en o desde Río de la Plata suma elementos dinamizadores, pero de modo ampliamente mayoritario no es comercio de Río de la Plata, tanto por los capitales invertidos como por la acumulación de los beneficios ${ }^{69}$. Observando desde el comercio ultramarino del complejo portuario rioplatense entre 1714 y 1778 se advierte que las conexiones extra-regionales en dirección del interior americano dibujan circuitos que muestran relaciones densas e intensas con los espacios delimitados por los complejos portuarios secos, al tiempo que las vinculaciones con Chile parecen mucho más importantes que las mantenidas con el Alto Perút7 .

Quedaba por probar esas percepciones que emergían del comercio ultramarino. Los datos expuestos en este trabajo parecen confirmarlas y mostrar la madurez de unas articulaciones económicas que no estuvieron ausentes de las consideraciones de Tomás Álvarez de Acevedo o del virrey Amat cuando el primero propuso crear un nuevo virreinato con capital en Buenos Aires en 1771 y el segundo lo apoyó en $1775^{71}$. Con este párrafo se podría cerrar el trabajo, ya que en lo concreto era lo que se quería demostrar.

Pero surge la pregunta en torno a para qué se lo quería demostrar, el problema general en que se inserta esa costosa pero en fin de cuentas pequeña demostración.

El problema general que está siempre presente es el de la dominación y si se eligió, hace mucho, la circulación mercantil como puerta de acceso fue por el afán de un por entonces joven investigador por insertar sus estudios de posgrado en una sólida tradición que vincula ambos aspectos. Desde sus comienzos en 1987 la investigación recibe de lleno lo que hoy se afianza como un quiebre epistemológico en los estudios sobre el Antiguo Régimen en general, y en el mundo hispánico en particular, con el progresivo abandono de las injerencias en las observaciones del paradigma estatal, que al centrar la mirada en

\footnotetext{
${ }_{69}$ Fernando Jumar, "Los comerciantes rioplatenses: su participación en el comercio legal español, 1720-1778”, en Fernando Jumar (Ed.), Mercantilismo y comercio en el mundo ibérico, Documentos de Trabajo 2, Facultad de Ciencias Jurídicas, Sociales y de la Comunicación, Buenos Aires, Universidad Argentina de la Empresa, 2002, pp. 5-28.

${ }^{70} \mathrm{~F}$. Jumar, "El comercio ultramarino por el complejo portuario rioplatense y la economía regional, 1714-1778, en Magallánica. Revista de Historia Moderna, 3, 5, 2016, pp. 171-259.

${ }^{71}$ Vicente G. Quesada, El virreinato del Río de la Plata, 1776-1810. Apuntamientos crítico-históricos para servir en la cuestión de límites entre la República Argentina y Chile, Buenos Aires, Tipografía de M. Biedma, 1881, pp. 40-41, 44-45.
} 
los dominios americanos de la Monarquía Hispánica lleva forzosamente al quiebre del paradigma colonial, que es derivado y complemento del estatal.

A partir de ello naturalmente se caen todas las explicaciones que miraban la economía de los dominios americanos de la Monarquía Hispánica partiendo y no llegando a la conclusión- de que se estaba ante conjuntos de mercados cautivos y fuentes parasitarias de renta. La colonialidad americana fue establecida desde lo teórico, dándose una virtuosa interacción entre los argumentos de la generación de las independencias americanas para legitimar la justicia de su causa ${ }^{72}$ y los análisis del imperialismo decimonónico desde la galaxia marxiana, operándose sobre la base de unidades de análisis anacrónicas y aplicando herramientas de análisis propias de las economías capitalistas laboriosamente adaptadas al Antiguo Régimen o adaptando -casi torturando los datos disponibles para ser utilizados con esas herramientas ${ }^{73}$. No es cuestión de negar lo obvio, como por ejemplo la explotación en América, pero simplemente no es explotación colonial y las puertas que se abren a la observación y reflexión invitan cada vez más a poner dentro de las sociedades americanas sus actores y principales beneficiarios en lugar de la "España" de la bibliografía. ${ }^{74}$

De todo ello, los resultados expuestos y su crítica (que se desarrolla en otro artícu$\mathrm{lo}^{75}$ ) dejan como conclusión posible que las vinculaciones entre los mercados americanos y extra-americanos se podrían explicar por necesidades de los más, en lugar del lujo de los

\footnotetext{
${ }^{72}$ Fernando Jumar, "Plumas en guerra. Argumentos y contrargumentos en torno a la independencia de las Provincias Unidas en Sud América y la naciente historiografía nacional argentina”, en Jornadas Bicentenario de la Independencia, Universidad Nacional de Tres de Febrero, Caseros, 29 y 30 de julio de 2016.

${ }^{73}$ Por ejemplo, los cálculos en torno a los PBI de fantásticos mercados internos "nacionales" en el Antiguo Régimen. Un ejemplo lo da, entre muchos, el modo en que John H. Coatsworth suma un 10\% por aquí para incluir el contrabando (p. 311, ¿̇por qué no el 20\% o el 50\% que sugieren otros "buenos cuberos"?), quita $25 \%$ por allá afín de armonizar datos y mantenerse dentro de márgenes que considera aceptables (p. 308), por aquí y por allí pone y saca gente a las estimaciones demográficas existentes o reorganiza como considera prudente los ramos de la contabilidad de la Real Hacienda, extrapola a toda la Argentina de 1800 (i?) escasos datos de salarios de Buenos Aires de fines del siglo XVIII y de Corrientes de los años 1830. John H. Coatsworth, "El Estado y la actividad económica colonial”, en Enrique Tandeter (Dir.); Jorge Hidalgo Lehuedé (Co-dir.), Procesos americanos hacia la redefinición colonial, Historia General de América Latina, Tomo IV, España, s/l, Ediciones de la UNESCO/Editorial Trotta, 2000, capítulo 14, pp. 300-323.

74 Planteado el problema desde una perspectiva más amplia, se puede considerar el trabajo forzado de americanos originarios en Huancavelica (Contreras, Povea Moreno) y de europeos en Almadén (Belinberg, Menéndez Navarro, Dobado González) y se vería que esas personas eran víctimas de la misma explotación y estaban condenadas al mismo tipo de muerte. De un modo u otro se trata de los vencidos en cada sociedad. Carlos Contreras, La ciudad del mercurio. Huancavelica, 1570-1700, Lima, Instituto de Estudios Peruanos, 1982; Isabel Povea Moreno, "Retrato de una decadencia. Régimen laboral y sistema de explotación en Huancavelica, 1784-1814”, Tesis de doctorado inédita, Universidad de Granada, 2011; Germán Belinberg, "El 'informe secreto' de Mateo Alemán sobre el trabajo forzoso en las minas de Almadén”, en Estudios de Historia Social: revista del Instituto de Estudios de Sanidad y Seguridad Social, 2-3, 1977, pp. 357-443; Alfredo Menéndez Navarro, "Un testimonio médico sobre las condiciones de vida y trabajo de los mineros de Almadén en la segunda mitad del siglo XVIII: el prólogo del Catástrofe morboso de las Minas Mercuriales de la Villa de Almadén del Azogue (1778) de José Parés y Franqués (+1798)”, en Dinamys: Acta Hispanica ad Medicinæ Scientiarumque Historiam Illustradam, 11, 1991, pp. 147-196; Rafael Dobado González, "El trabajo en las minas de Almadén, 1750-1855”, Tesis de doctorado inédita, Universidad Complutense de Madrid, 1989.

${ }^{75}$ F. Jumar, "En torno a la circulación".
} 
menos y diseños institucionales pensados para empobrecer unas sociedades en beneficio de otras. Necesidades que no son las de subsistencia física sino estamental (más si se observa en sincronía lo que costaba subsistir físicamente en Europa). No es demasiado, pero si las hipótesis planteadas sumasen confirmaciones cada vez tendría menos asidero la parte de la explicación de la colonialidad americana relacionada con el comercio tal como se la ha venido sosteniendo. La cautividad de los mercados americanos en relación a los europeos sería el resultado de problemas internos de las sociedades americanas y no de diseños institucionales destinados a generar la exacción colonial. Los comerciantes dejan de ser agentes del imperialismo dispuestos hasta a explotar a sus hijos y nietos para mayor beneficio de "España". Hasta tal vez sea posible que la mayor parte de la riqueza generada en América sobre la base de la explotación del trabajo de los vencidos de la conquista, de los esclavizados y de los hispano-criollos que no pertenecían a los grupos dominantes se haya quedado en América y la que salió, no lo hizo mediante mecanismos compulsivos sino porque hubo americanos que lo juzgaron conveniente para sus intereses.

Se suman debilitamientos a los paradigmas de la historia tradicional al observar el estado de las investigaciones sobre la fiscalidad en Hispanoamérica durante el Antiguo Régimen y más aún si se consideran las informaciones sobre la fiscalidad en los dominios peninsulares. ${ }^{76}$ Se esfuma la visión de las sociedades americanas en tanto que fuentes parasitarias de renta en beneficio de la metrópolis para emerger conjuntos más amplios a los que se intenta explotar por igual. Haciendo foco en las investigaciones que ponen el acento no sólo en la recaudación sino también en el gasto fiscal se observa, además de que la mayor parte de lo recaudado en América se gastaba allí, que no siempre la transferencia de recursos de la Real Hacienda fue en la dirección América-Europa o que buena parte del costo y de la "cuota de sangre" de la defensa de la parte americana del conjunto pesó sobre las sociedades de los dominios europeos ${ }^{77}$. Se aleja aún más la colonialidad clásica al observar a los americanos, que tozudamente se niegan a pagar derechos, incentivar la gracia real a través de préstamos y donativos ${ }^{78}$. Donativos y préstamos, sí. Impuestos, no.

\footnotetext{
${ }^{76}$ P. e. Fernando Ramos Palencia y Bartolomé Yun Casalilla presentan una colección de textos. Entre los que se dedican al mundo hispánico se ven las tensiones entre los viejos lenguajes y las nuevas preguntas y evidencias. Fernando Ramos Palencia; Bartolomé Yun Casalilla (Eds.), Economía política desde Estambul a Potosí. Ciudades-Estado, imperios y mercados en el Mediterráneo y en el Atlántico ibérico, c. 1200-1800, Valencia, Universitat de València, 2012.

${ }^{77}$ Aunque no se incluye el análisis numérico de esta variable, se la hace intervenir en el análisis del caso abordado en F. Jumar; Ma . E. Sandrín, "El gasto público” como dinamizador de la economía local. Río de la Plata, en la primera mitad del siglo XVIII”, en Ernest Sánchez Santiró (Coord.), El gasto público en los Imperios Ibéricos, siglo XVIII, México, Instituto Mora, 2015, pp. 205-272.

${ }^{78}$ Guillermina del Valle Pavón, "Contraprestaciones por los servicios financieros del Consulado de México y sus miembros para la guerra contra Gran Bretaña, 1779-1783”, en Revista Complutense de Historia de América, 41, 2015, pp. 149-171; Javier Kraselsky, "Las corporaciones mercantiles de Buenos Aires y los préstamos y donativos graciosos", en Illes i Imperis, 18, 2016, pp. 107-134.
} 
O lo menos que se pueda, ya que no pueden ser convertidos en servicios a la hora de obligar al rey a conceder privilegios. $Y$ aun lo que se paga es debido a la voluntad de pagar, ya que la Corona nunca tuvo en América la capacidad que sí tuvo en los dominios peninsulares para tratar de imponer sus puntos de vista por la violencia. De allí las resistencias al avance de la monarquía administrativa y la defensa de la compuesta, que asegura a los americanos la pervivencia policentrismo en el ejercicio del poder y el disfrute de sus beneficios.

El avance de la monarquía administrativa es lento pero sostenido, emergente de un entretejido de negociaciones en las que la Corona dispensa la gracia en favor de unos $\mathrm{u}$ otros en la medida que logra adelantar su proyecto. Cada vez que puede se impone y el nacimiento del Virreinato del Río de la Plata puede ser entendido como una serie de procesos que convergen en un punto y cuajan en una creación institucional cuya efímera vida debe ser analizada ante todo en función de la coyuntura más que de las agendas de los actores locales y de la Corona.

Sin embargo, y si se tiene en cuenta cómo terminó el Virreinato del Río de la Plata, se puede proponer que los lazos económicos existentes entre algunos de los espacios que se incluyeron en él fueron más fuertes que las intenciones de la Corona y el conflicto emergente de la crisis desatada en 1808 . No parece desatinado pensar que si el Tucumán, Cuyo y Río de la Plata (menos la banda norte) terminaron conformando la República Argentina, una de las bases principales de la explicación puede ser su integración económica durante el Antiguo Régimen, o lo que es lo mismo, el entretejido profundo de redes de intereses complementarios y, sin duda, también contradictorios entre los grupos dominantes en cada espacio regional.

Pero con un cambio mayor. Si en el análisis de la formación del espacio económico rioplatense la integración entre el núcleo de sus componentes se debe en primer término a un concierto de voces que haciendo primar la complementariedad por sobre el conflicto lograron durante más de dos siglos un sistema de dominación altamente estable, tras 1810, en la formación de la República Argentina y la Oriental del Uruguay hay que prestar más atención a procesos que desbalancearon los equilibrios. En el caso uruguayo, parece necesario revisar las explicaciones que ponen el acento de su creación en los primeros estertores del imperialismo decimonónico. En el caso argentino, sigue siendo central el papel de Buenos Aires. El quiebre del Antiguo Régimen rompió los equilibrios y Buenos Aires -como se ve desde la historia política- emprende esfuerzos 
por ocupar el lugar de la Corona ${ }^{79}$. Mediante la negociación, pero más por la violencia y el control económico, genera un nuevo espacio de planificación que será el mercado interno de la República Argentina ${ }^{80}$.

De este modo, es posible entonces que los circuitos permitan enriquecer las explicaciones de los procesos de formación de los Estados-nación, tal como ya lo había señalado C. S. Assadourian, aunque explicando el proceso de otro modo. Suma perspectivas a los enfoques centrados en la historia política que analiza tales procesos desde la crisis de la monarquía en adelante y tornando comprensibles algunas trayectorias que parecen inciertas porque habrían estado en buena parte guiadas por intereses económicos anudados de antiguo, que ni la revolución ni la guerra lograron quebrar, aunque sí resignificar bajo los imperativos de Buenos Aires.

\footnotetext{
${ }_{79}$ En los aspectos económicos, el objetivo porteño se asocia al modo a través del cual puede realizar su potencial productivo ganadero en los mercados ultramarinos. Para los rioplatenses, poco importa quién compra sus cueros y su carne salada, y de allí nacen complementariedades y competencias con el comercio ultramarino. Lo esencial que se necesita recordar ahora es que para que los rioplatenses tengan clientes tiene que haber navíos que llegan a su complejo portuario, y esos navíos llegan si es para vender mercaderías. De modo que la región Río de la Plata asegura el nexo entre el Atlántico y los espacios interiores sobre todo para que se vacíen las bodegas que recibirán sus cueros. Durante un breve momento a comienzos de 1820 Buenos Aires creyó que podría ser viable como Estado autónomo, pero rápidamente se dio cuenta de que debía poder controlar la circulación interior para continuar siendo la interlocutora privilegiada del comercio ultramarino.

${ }^{80}$ Viviana Conti; Fernando Jumar, "El impacto de la independencia en las articulaciones y desarticulaciones regionales: ensayo comparativo entre la región Río de la Plata y la región Salto-jujeña”, en Revista Estudios del ISHIR. Unidad Ejecutora en Red, Investigaciones Socio Históricas Regionales, Unidad Ejecutora en Red/CONICET, 2, 2, 2012, pp. 1-21, http://web2.rosario-conicet.gov.ar/ojs/index.php/revistaISHIR/article/view/123 (consulta 10/o2/2019); Fernando Jumar, "Lo que la revolución se llevó: la región Río de la Plata como espacio homogéneo”, en Boletín del Instituto de Historia Argentina y Americana Dr. Emilio Ravignani, Tercera Serie, 33, 2011, pp. 141-148.
} 


\section{Apéndice 1. Tabla}

Tabla 1. Categorías y sub-categorías para clasificar los bienes

\begin{tabular}{|c|c|}
\hline Alimentación & \begin{tabular}{|c|}
$\begin{array}{c}\text { Cant. de } \\
\text { registros de } \\
\text { bienes }\end{array}$ \\
\end{tabular} \\
\hline ALIMENTOS INDIFERENCIADOS & 439 \\
\hline AVES EN CONSERVA & 29 \\
\hline BEBIDA & 200 \\
\hline BEBIDA ALCOHOLICA & 5.865 \\
\hline BOVINO EN CONSERVA/SALADO & 186 \\
\hline CERDO CHACINADOS & 96 \\
\hline CERDO EN CONSERVA & 15 \\
\hline CERDO FIAMBRES & 187 \\
\hline CEREAL & 502 \\
\hline CONDIMENTO & 1.415 \\
\hline CONSERVA VEGETAL & 21 \\
\hline DERIVADO ANIMAL & 531 \\
\hline DERIVADO VEGETAL & 2.416 \\
\hline DULCES Y REPOSTERIA & 388 \\
\hline FRUTA DISECADA & 1.574 \\
\hline FRUTA EN CONSERVA & 219 \\
\hline FRUTA FRESCA & 220 \\
\hline FRUTOS SECOS & 748 \\
\hline HARINAS & 372 \\
\hline INFUSION & 3.062 \\
\hline LEGUMBRE SECA & 379 \\
\hline PANIFICADOS & 581 \\
\hline PASTA & 310 \\
\hline PESCADO EN CONSERVA/SALADO & 141 \\
\hline SEMILLAS & 38 \\
\hline VEGETALES FRESCOS & 625 \\
\hline \multicolumn{2}{|l|}{ Contenedores } \\
\hline VARIA & 682 \\
\hline LINO & 1 \\
\hline PELUQUERIA & 1 \\
\hline SANITARIOS & 1 \\
\hline \multicolumn{2}{|l|}{ Cuchillería } \\
\hline VARIA & 2.163 \\
\hline COCINA & 2 \\
\hline COSECHA & 6 \\
\hline CURTIEMBRE & 1 \\
\hline EXPLOTACION GANADO & 2 \\
\hline NAVEGACION & 2 \\
\hline ZAPATERIA & 4 \\
\hline
\end{tabular}

\begin{tabular}{|c|c|}
\hline Animal vivo & \begin{tabular}{|c} 
Cant. de \\
registros de \\
bienes \\
\end{tabular} \\
\hline AVES & 9 \\
\hline AVES DE CORRAL & 726 \\
\hline BOVINO & 15 \\
\hline CANINO & 1 \\
\hline EQUINO & 88 \\
\hline MULAR & 108 \\
\hline OVINO & 7 \\
\hline PORCINO & 6 \\
\hline \multicolumn{2}{|c|}{ Armas y pertrechos bélicos } \\
\hline VARIA & 2 \\
\hline ARMAS BLANCAS & 95 \\
\hline ARMAS DE FUEGO & 207 \\
\hline POLVORA & 89 \\
\hline \multicolumn{2}{|l|}{ Artículos del fumador } \\
\hline ACCESORIOS FUMADOR & 15 \\
\hline CONTENEDOR & 34 \\
\hline TABACO & 22 \\
\hline \multicolumn{2}{|l|}{ Cerrajería } \\
\hline CANDADOS & 159 \\
\hline CERRADURAS & 1 \\
\hline CERRAJERIA & 81 \\
\hline CERRAMIENTOS & 73 \\
\hline HERRAJES & 34 \\
\hline \multicolumn{2}{|l|}{ Cordelería } \\
\hline VARIA & 3 \\
\hline NAVEGACION & 18 \\
\hline \multicolumn{2}{|l|}{ Ferretería } \\
\hline VARIA & 218 \\
\hline GANADERIA & 53 \\
\hline LINO & 1 \\
\hline ZAPATERIA & 6 \\
\hline \multicolumn{2}{|c|}{ Higiene y arreglo personal } \\
\hline VARIA & 696 \\
\hline BARBERIA & 4 \\
\hline SANITARIOS & 91 \\
\hline \multicolumn{2}{|l|}{ Derivado vegetal } \\
\hline VARIA & 264 \\
\hline COMBUSTIBLE & 3 \\
\hline
\end{tabular}


Tabla 1. Categorías y sub-categorías para clasificar los bienes (cont.)

\begin{tabular}{|c|c|}
\hline $\begin{array}{l}\text { Equipamiento productivo / } \\
\text { Herramientas }\end{array}$ & $\begin{array}{c}\text { Cant. de } \\
\text { registros de } \\
\text { bienes }\end{array}$ \\
\hline AFILADO & 8 \\
\hline AGRICOLA & 296 \\
\hline ARMERIA & 1 \\
\hline BARBERIA & 13 \\
\hline CARPINTERIA & 125 \\
\hline CAZA Y PESCA & 10 \\
\hline CERNIDO & 129 \\
\hline CONSTRUCCION & 26 \\
\hline COSTURA & 24 \\
\hline DE AJUSTE & 4 \\
\hline DE CAVAR & 97 \\
\hline DE CORTE & 771 \\
\hline DE GOLPE & 36 \\
\hline DESTILADO & 14 \\
\hline DULCES Y REPOSTERIA & 3 \\
\hline ENCURTIDO & 1 \\
\hline EXPERIMENTACION & 3 \\
\hline GANADERIA & 47 \\
\hline HERRERIA & 11 \\
\hline ILUMINACION & 1 \\
\hline LIBRERIA & 5 \\
\hline MEDICINA & 28 \\
\hline METROLOGIA & 73 \\
\hline NAVEGACION & 12 \\
\hline ORFEBRERIA & 19 \\
\hline PANADERIA & 8 \\
\hline PEDRERIA & 1 \\
\hline PERFORACION & 46 \\
\hline PULIDO & 2 \\
\hline SILLERIA & 1 \\
\hline TEJEDURIA & 2 \\
\hline TONELERIA & 7 \\
\hline TORNERIA & 11 \\
\hline UTILLAJE PROFESIONAL INDIF. & 46 \\
\hline ZAPATERIA & 59 \\
\hline \multicolumn{2}{|l|}{ Indumentaria } \\
\hline VARIA & 1.917 \\
\hline ALGODON & 634 \\
\hline LANA & 5.040 \\
\hline LINO & 1.079 \\
\hline SEDA & 1.408 \\
\hline \multicolumn{2}{|l|}{ Indumentaria religiosa } \\
\hline VARIA & 3 \\
\hline LANA & 24 \\
\hline SEDA & 14 \\
\hline
\end{tabular}

\begin{tabular}{|c|c|}
\hline Derivado animal & $\begin{array}{c}\text { Cant. de } \\
\text { registros de } \\
\text { bienes }\end{array}$ \\
\hline AVICOLA & 10 \\
\hline BOVINO & 570 \\
\hline BOVINO CURTIDO & 536 \\
\hline BOVINO JABONERIA & 1.421 \\
\hline BOVINO SALADERO & 203 \\
\hline CAMELIDO FIBRA & 43 \\
\hline EQUINO & 13 \\
\hline EQUINO SALADERO & 4 \\
\hline LOBO MARINO & 2 \\
\hline LOBO MARINO SALADERO & 1 \\
\hline OVINO & 434 \\
\hline OVINO CURTIDO & 1.378 \\
\hline OVINO FIBRA & 499 \\
\hline PELETERIA & 269 \\
\hline PORCINO & 6 \\
\hline PORCINO SALADERO & 1 \\
\hline \multicolumn{2}{|l|}{ Iluminación } \\
\hline COMBUSTIBLE & 673 \\
\hline ENCENDIDO & 9 \\
\hline LUMINARIAS Y AFINES & 315 \\
\hline PABILO & 260 \\
\hline \multicolumn{2}{|l|}{ Impresos } \\
\hline EDUCACION & 38 \\
\hline IMPRESOS PIADOSOS & 235 \\
\hline LEYES & 8 \\
\hline LIBROS & 259 \\
\hline MAPAS & 4 \\
\hline \multicolumn{2}{|l|}{ Indumentaria accesorio } \\
\hline VARIA & 2.588 \\
\hline ALGODON & 183 \\
\hline BISUTERIA & 612 \\
\hline CUERO DE BURRO: & 107 \\
\hline JOYERIA & 17 \\
\hline LANA & 1.148 \\
\hline LANA VICUÑA & 3 \\
\hline LINO & 758 \\
\hline MARROQUINERIA & 16 \\
\hline MARROQUINERIA SEDA & 15 \\
\hline PAJA & 144 \\
\hline SEDA & 1.054 \\
\hline SUELA & 1 \\
\hline TEXTIL & 960 \\
\hline TEXTILSEDA & 115 \\
\hline VICUÑA & 2 \\
\hline
\end{tabular}


Tabla 1. Categorías y sub-categorías para clasificar los bienes (cont.)

\begin{tabular}{|c|c|c|c|}
\hline Insumo productivo & \begin{tabular}{|c|} 
Cant. de \\
registros de \\
bienes
\end{tabular} & Mercería & $\begin{array}{c}\text { Cant. de } \\
\text { registros de } \\
\text { bienes }\end{array}$ \\
\hline VARIA & 188 & VARIA & 9 \\
\hline HIERRO TONELERIA & 1 & ABROCHADORES & 12 \\
\hline TONELERIA & 2 & BOTONERIA & 1.572 \\
\hline \multicolumn{2}{|l|}{ Juego y esparcimiento } & CANUTILLOS & 20 \\
\hline BELLAS ARTES & 1 & CASCABELES & 44 \\
\hline CARETAS & 6 & CINTAS & 4.525 \\
\hline CUERDAS P/INTRUMENTOS MUSICALES & 106 & CINTILLOS & 3 \\
\hline INSTRUMENTO MUSICAL & 37 & CORDONERIA & 13 \\
\hline JUEGOS DE ADULTO & 18 & CORSETERIA & 5 \\
\hline JUGUETES & 12 & COSTURA & 380 \\
\hline PARTITURAS & 3 & FLECOS & 18 \\
\hline PIROTECNIA & 5 & GALONES & 238 \\
\hline PITOS & 40 & HEBILLAS & 519 \\
\hline \multicolumn{2}{|l|}{ Librería y escritorio } & HILO DE ZAPATERO & 47 \\
\hline MARROQUINERIA & 2 & HILOS & 2.955 \\
\hline PAPEL & 2.111 & PATILLAS HEBILLA & 3 \\
\hline \multicolumn{2}{|l|}{ Mano de obra } & RASTREADORES & 2 \\
\hline ESCLAVO CON AMO & 719 & ZAPATERIA & 33 \\
\hline ESCLAVO CON OFICIO & 3 & \multicolumn{2}{|l|}{ Metal / Mineral } \\
\hline ESCLAVO EN VENTA & 37 & VARIA & 180 \\
\hline ESCLAVO POSIBLE COMPRA/VENTA & 655 & CARPINTERIA & 1 \\
\hline LIBRE & 10 & CLAVAZON & 1 \\
\hline \multicolumn{2}{|l|}{ Mat. de construcc. / reparaciones } & HIERRO & 349 \\
\hline CLAVAZON & 280 & HIERRO CERRAMIENTOS & 5 \\
\hline CONSTRUCCION & 289 & HIERRO EDIFICACION & 1 \\
\hline HERRERIA DE OBRA & 42 & HIERRO NAVEGACION & 2 \\
\hline MADERA & 265 & NAVEGACION & 4 \\
\hline MADERA CERRAMIENTOS & 91 & \multicolumn{2}{|l|}{ Mobiliario y decoración } \\
\hline MADERA CORRAL & 4 & VARIA & 1.327 \\
\hline MADERA MOBILIARIO & 14 & ALGODON & 1 \\
\hline MADERA OBRA & 160 & BLANCO & 2 \\
\hline MADERA SILLERIA & 1 & LANA & 5 \\
\hline MADERA TONELERIA & 39 & LINO & 3 \\
\hline MADERA TRANSPORTES & 32 & REDONDELES & 8 \\
\hline MADERA ZAPATERIA & 44 & SEDA & 1 \\
\hline NAVEGACION & 52 & SILLERIA ZAPATERIA & 1 \\
\hline PLOMERIA & 7 & ZAPATERIA & 2 \\
\hline TONELERIA & 14 & \multicolumn{2}{|l|}{ Servicio de mesa } \\
\hline TRANSPORTES & 6 & VARIA & 1.249 \\
\hline TROMPAS & 71 & CRISTALERIA & 356 \\
\hline VIDRIOS & 94 & CUBERTERIA & 353 \\
\hline \multicolumn{2}{|l|}{ Medios de transporte } & \multicolumn{2}{|l|}{ Talabartería y aperos } \\
\hline VARIA & 3 & VARIA & 3.568 \\
\hline MEDIOS DE TRANSPORTE & 59 & ALGODON & 10 \\
\hline PARTES & 43 & CUCHILLERIA & 200 \\
\hline & & EQUIPAJE & 1 \\
\hline & & OVINO & 2 \\
\hline
\end{tabular}


Tabla 1. Categorías y sub-categorías para clasificar los bienes (cont. y fin)

\begin{tabular}{|l|r|}
\hline Textil blanco & \multicolumn{1}{|c|}{$\begin{array}{c}\text { Cant. de } \\
\text { registros de } \\
\text { bienes }\end{array}$} \\
\hline VARIA & 8 \\
\hline ALGODON & 18 \\
\hline LANA & 373 \\
\hline LINO & 11 \\
\hline Textil fibras & 168 \\
\hline ALGODON & 3 \\
\hline CAÑAMO & 54 \\
\hline LINO & 34 \\
\hline PITA & 3 \\
\hline PITA ZAPATERIA & 3 \\
\hline Textil tela & 1.944 \\
\hline ALGODON & 9.274 \\
\hline CAÑAMO & 12.411 \\
\hline LANA & 2.357 \\
\hline LINO & \\
\hline SEDA & \\
\hline
\end{tabular}

\begin{tabular}{|l|r|}
\hline Uso religioso & \multicolumn{1}{|c|}{$\begin{array}{c}\text { Cant. de } \\
\text { registros de } \\
\text { bienes }\end{array}$} \\
\hline VARIA & 87 \\
\hline BISUTERIA & 71 \\
\hline SEDA & 578 \\
\hline Útil de cocina & 14 \\
\hline COCCION & 76 \\
\hline CONJUNTOS & 336 \\
\hline PREPARACION & 31 \\
\hline Colorantes & 113 \\
\hline Documentos oficiales & 25 \\
\hline Documentos privados & 5.547 \\
\hline Efectos de Castilla sin diferenciar & 219 \\
\hline Equipaje sin valor mercantil & 1.619 \\
\hline Zapatería & 37 \\
\hline Metales preciosos & 253 \\
\hline Óptica
\end{tabular}

Fuente: RegAduAR.

Total de registros de bienes

112.790 
Tabla 2.a. Organización de la información por destinos. Circulación extra-regional

\begin{tabular}{|l|r|}
\hline \multicolumn{2}{|c|}{ 01. CENTRO } \\
\hline & $\begin{array}{r}\text { Cant. } \\
\text { registros }\end{array}$ \\
\hline CENTRO CBA (CALAMUCHITA) & 108 \\
\hline CENTRO CBA (CORDOBA) & 6.825 \\
\hline CENTRO CBA (JURISDICCION) & 33 \\
\hline CENTRO CBA (PUNTA DEL AGUA) & 28 \\
\hline CENTRO CBA (R CUARTO) & 8 \\
\hline CENTRO CBA (R SEGUNDO) & 12 \\
\hline CENTRO CBA (R TERCERO) & 66 \\
\hline CENTRO CBA (SIERRAS DE CBA) & 18 \\
\hline CENTRO CBA (TRASLASIERRA) & 1.752 \\
\hline CENTRO N (SGO DEL ESTERO) & 2.107 \\
\hline CENTRO N (SM DEL TUCUMAN) & 782 \\
\hline CENTRO O (CATAMARCA) & 230 \\
\hline CENTRO O (LA RIOJA) & 108 \\
\hline CENTRO TUC (JURISDICCION) & 12.083 \\
\hline Total
\end{tabular}

\begin{tabular}{|l|r|}
\hline \multicolumn{2}{|c|}{ 02. NORTE } \\
\hline NORTE (JUJUY) & 2.008 \\
\hline NORTE (SALTA) & 5.128 \\
\hline NORTE AP & 196 \\
\hline NORTE AP (AZANGARO) & 6 \\
\hline NORTE AP (CARABAYA) & 3 \\
\hline NORTE AP (CHAYANTA) & 1 \\
\hline NORTE AP (CHICHAS) & 3 \\
\hline NORTE AP (CHUCUITO) & 16 \\
\hline NORTE AP (CHULUMANI) & 23 \\
\hline NORTE AP (COCHABAMBA) & 22 \\
\hline NORTE AP (CUZCO) & 11 \\
\hline NORTE AP (LA PAZ) & 304 \\
\hline NORTE AP (LA PLATA) & 227 \\
\hline NORTE AP (LAMPA) & 4 \\
\hline NORTE AP (ORURO) & 95 \\
\hline NORTE AP (POTOSI) & 24 \\
\hline NORTE AP (PUNO) & 13 \\
\hline NORTE AP (STA CRUZ DE LA SIERRA) & 11.729 \\
\hline NORTE AP (STA ROSA DE OCOPA) & 3.627 \\
\hline NORTE AP (TARIJA) & 24 \\
\hline NORTE AP (TOMINA) & \\
\hline NORTE AP (YAMPARAES) & 13 \\
\hline TOtal & 2 \\
\hline
\end{tabular}

Fuente: RegAduAR.

\begin{tabular}{|c|c|}
\hline \multicolumn{2}{|l|}{ 03. NORTE } \\
\hline & $\begin{array}{c}\text { Cant. } \\
\text { registros }\end{array}$ \\
\hline BAJO PERU & 3 \\
\hline BAJO PERU (AREQUIPA) & 11 \\
\hline BAJO PERU (CAJAMARCA) & 8 \\
\hline BAJO PERU (CALLAO) & 3 \\
\hline BAJO PERU (LIMA) & 353 \\
\hline BAJO PERU (TARAPACA) & 86 \\
\hline CHILE & 524 \\
\hline CHILE (CONCEPCION) & 21 \\
\hline CHILE (COPIAPO) & 145 \\
\hline CHILE (COQUIMBO) & 3 \\
\hline CHILE (SGO DE CHILE) & 3.501 \\
\hline CHILE (VALPARAISO) & 20 \\
\hline CUYO & 20 \\
\hline CUYO (MENDOZA) & 4.935 \\
\hline CUYO (PUNTA DE AGUA, S LUIS) & 10 \\
\hline CUYO (SAN JUAN) & 4.248 \\
\hline CUYO (SAN LUIS) & 608 \\
\hline CUYO (TUNUYAN) & 20 \\
\hline Total & 14.519 \\
\hline
\end{tabular}

\begin{tabular}{|l|r|}
\hline \multicolumn{2}{|c|}{ 04. PARAGUAY } \\
\hline PARAGUAY & 5.060 \\
\hline PARAGUAY (ASUNCION) & 3.614 \\
\hline PARAGUAY (ATYRA) & 14 \\
\hline PARAGUAY (CAAZAPA) & 17 \\
\hline PARAGUAY (PIRAYU) & 46 \\
\hline PARAGUAY (TIBICUARIMINI) & 2 \\
\hline PARAGUAY (VILLA RICA) & 222 \\
\hline PARAGUAY (YUTI) & 21 \\
\hline PARAGUAY (ÑEEMBUCU) & 3 \\
\hline PARAGUAY PMIS CANDELARIA & 98 \\
\hline PARAGUAY PMIS CORPUS & 59 \\
\hline PARAGUAY PMIS COSME & 80 \\
\hline PARAGUAY PMIS ITAPUA & 84 \\
\hline PARAGUAY PMIS JESUS & 84 \\
\hline PARAGUAY PMIS LORETO & 78 \\
\hline PARAGUAY PMIS S IGNACIO GUAZU & 16 \\
\hline PARAGUAY PMIS S IGNACIO MINI & 78 \\
\hline PARAGUAY PMIS SANTIAGO & 31 \\
\hline PARAGUAY PMIS STA ANA & 60 \\
\hline PARAGUAY PMIS STA ROSA & 83 \\
\hline PARAGUAY PMIS TRINIDAD & 15 \\
\hline Total & 9.765 \\
\hline
\end{tabular}


Tabla 2.b. Organización de la información por espacios. Circulación intrarregional

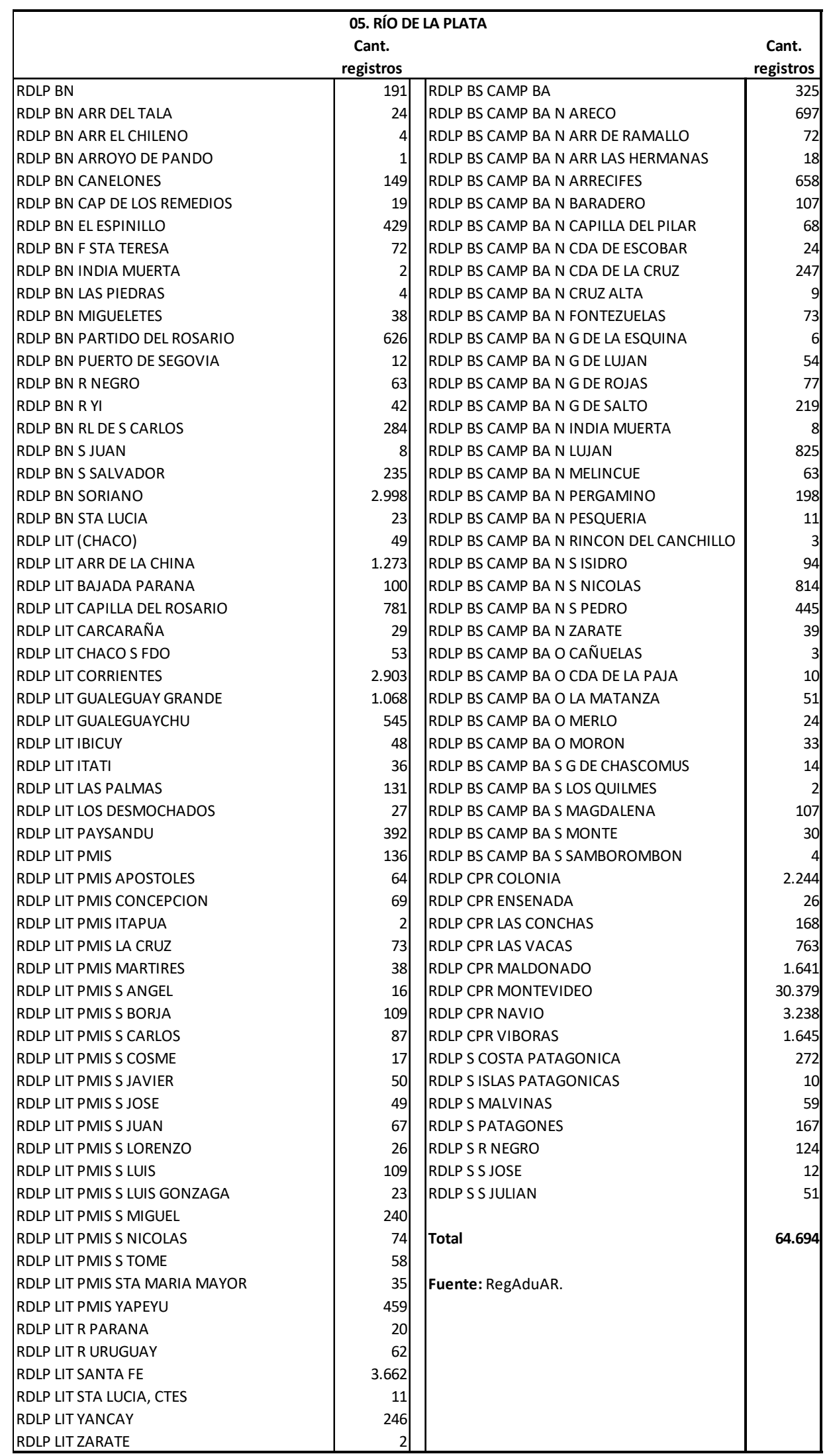


Tabla 5. Intensidad y densidad de tratos con Norte, notas de aduana, Aduana de Buenos Aires,1779-1783

\begin{tabular}{|c|c|c|c|c|}
\hline Año & Ruta & Destino & Intensidad & Densidad \\
\hline \multirow[t]{5}{*}{1779} & 01. Centro & & 135 & 2.970 \\
\hline & 02. Norte & [Migrados de Córdoba] & 30 & 573 \\
\hline & 02. Norte & Salta-Jujuy & 77 & 2.085 \\
\hline & 02. Norte & Alto Perú & 68 & 1.031 \\
\hline & & Sub-total 1779 & 175 & 3.689 \\
\hline \multirow[t]{5}{*}{1780} & 01. Centro & & 156 & 1.363 \\
\hline & 02. Norte & [Migrados de Córdoba] & 36 & 294 \\
\hline & 02. Norte & Salta-Jujuy & 42 & 482 \\
\hline & 02. Norte & Alto Perú & 92 & 856 \\
\hline & & Sub-total 1780 & 170 & 1.632 \\
\hline \multirow[t]{5}{*}{1781} & 01. Centro & & 97 & 780 \\
\hline & 02. Norte & [Migrados de Córdoba] & 21 & 147 \\
\hline & 02. Norte & Salta-Jujuy & 39 & 208 \\
\hline & 02. Norte & Alto Perú & 43 & 375 \\
\hline & & Sub-total 1781 & 103 & 730 \\
\hline \multirow[t]{5}{*}{1782} & 01. Centro & & 132 & 1.004 \\
\hline & 02. Norte & [Migrados de Córdoba] & 36 & 232 \\
\hline & 02. Norte & Salta-Jujuy & 74 & 1.090 \\
\hline & 02. Norte & Alto Perú & 76 & 752 \\
\hline & & Sub-total 1782 & 186 & 2.074 \\
\hline \multirow[t]{6}{*}{1783} & 01. Centro & & 172 & 2.089 \\
\hline & 02. Norte & [Migrados de Córdoba] & 88 & 927 \\
\hline & 02. Norte & Salta-Jujuy & 157 & 3.271 \\
\hline & 02. Norte & Alto Perú & 140 & 1.579 \\
\hline & & Sub-total 1783 & 385 & 5.777 \\
\hline & & Total & 1.019 & 13.902 \\
\hline
\end{tabular}

Fuente: RegAduAR. 
Tabla 9. Intensidad y densidad, circulacion intrarregional rioplatense, notas de aduana, Aduana de Buenos Aires, 1779-1783

\begin{tabular}{|c|c|c|}
\hline Sub-conjunto regional & Intensidad & Densidad \\
\hline \multicolumn{3}{|l|}{ BANDA NORTE } \\
\hline BN sin diferenciar & 42 & 191 \\
\hline Arr. del Tala & 4 & 24 \\
\hline Arr. El Chileno & 1 & 4 \\
\hline Arr. de Pando & 1 & 1 \\
\hline Canelones & 9 & 149 \\
\hline Capilla de los Remedios & 4 & 19 \\
\hline El Espinillo & 69 & 429 \\
\hline Fte. Santa Teresa & 9 & 72 \\
\hline India Muerta (BN) & 1 & 2 \\
\hline Las Piedras & 1 & 4 \\
\hline Migueletes & 6 & 38 \\
\hline Pdo. del Rosario & 83 & 626 \\
\hline Segovia & 1 & 12 \\
\hline Río Negro & 13 & 63 \\
\hline Río Yi & 4 & 42 \\
\hline Real de San Carlos & 41 & 284 \\
\hline San Juan (BN) & 2 & 8 \\
\hline San Salvador & 42 & 235 \\
\hline Soriano & 444 & 2.998 \\
\hline Santa Lucía & 3 & 23 \\
\hline Sub-total Banda norte & 780 & 5.224 \\
\hline \multicolumn{3}{|l|}{ BANDA SUR } \\
\hline Campaña de BA & 32 & 325 \\
\hline Areco & 118 & 697 \\
\hline Arr. de Ramallo & 6 & 72 \\
\hline Arr. Las Hermanas & 2 & 18 \\
\hline Arrecifes & 82 & 658 \\
\hline Baradero & 15 & 107 \\
\hline Capilla del Pilar & 7 & 68 \\
\hline Cañada de Escobar & 4 & 24 \\
\hline Cañada de la Cruz & 39 & 247 \\
\hline Cruz Alta & 2 & 9 \\
\hline Fontezuelas & 10 & 73 \\
\hline Guardia de la Esquina & 1 & 6 \\
\hline Guardia de Luján & 13 & 54 \\
\hline Guardia de Rojas & 4 & 77 \\
\hline Guardia del Salto & 29 & 219 \\
\hline India Muerta (BS) & 2 & 8 \\
\hline Luján & 88 & 825 \\
\hline Melincué & 5 & 63 \\
\hline Pergamino & 20 & 198 \\
\hline Pesquería & 3 & 11 \\
\hline Rincón del Canchillo & 1 & 3 \\
\hline San Isidro & 20 & 94 \\
\hline San Nicolás & 72 & 814 \\
\hline San Pedro & 45 & 445 \\
\hline Zárate & 1 & 39 \\
\hline Cañuelas & 2 & 3 \\
\hline Cañada de la Paja & 2 & 10 \\
\hline La Matanza & 8 & 51 \\
\hline Merlo & 4 & 24 \\
\hline Morón & 7 & 33 \\
\hline Guardia de Chascomús & 4 & 14 \\
\hline Los Quilmes & 1 & 2 \\
\hline Magdalena & 19 & 107 \\
\hline Monte & 3 & 30 \\
\hline Samborombón & 1 & 4 \\
\hline Sub-total Banda sur & 672 & 5.432 \\
\hline
\end{tabular}

Fuente: RegAduAR.

\begin{tabular}{|c|c|c|}
\hline Sub-conjunto regional & Intensidad & Densidad \\
\hline \multicolumn{3}{|l|}{ COMPLEJO PORTUARIO } \\
\hline Colonia del Sacramento & 439 & 2.244 \\
\hline Ensenada de Barragán & 13 & 26 \\
\hline Las Conchas & 45 & 168 \\
\hline Las Vacas & 138 & 763 \\
\hline Maldonado & 181 & 1.641 \\
\hline Montevideo & 7.462 & 30.379 \\
\hline Navío anclado & 1.154 & 3.238 \\
\hline Las Víboras & 213 & 1.645 \\
\hline Sub-total compl. port. & 9.645 & 40.104 \\
\hline \multicolumn{3}{|l|}{ LITORAL } \\
\hline Arr. de la China & 143 & 1.273 \\
\hline Bajada del Paraná & 9 & 100 \\
\hline Capilla del Rosario & 46 & 781 \\
\hline Carcarañá & 5 & 29 \\
\hline Chaco & 4 & 102 \\
\hline Corrientes & 299 & 2.914 \\
\hline Gualeguay & 146 & 1.068 \\
\hline Gualeguaychú & 79 & 545 \\
\hline Ibicuy & 8 & 48 \\
\hline Itati & 3 & 36 \\
\hline Las Palmas & 19 & 131 \\
\hline Los Desmochados & 1 & 27 \\
\hline Paysandú & 40 & 392 \\
\hline Pmis sin especificar & 25 & 136 \\
\hline Pmis Apóstoles & 4 & 64 \\
\hline Pmis Concepción & 6 & 69 \\
\hline Pmis Itapuá & 1 & 2 \\
\hline Pmis La Cruz & 4 & 73 \\
\hline Pmis Mártires & 4 & 38 \\
\hline Pmis San Ángel & 3 & 16 \\
\hline Pmis San Borja & 9 & 109 \\
\hline Pmis San Carlos & 7 & 87 \\
\hline Pmis San Cosme & 1 & 17 \\
\hline Pmis San Javier & 5 & 50 \\
\hline Pmis San José & 5 & 49 \\
\hline Pmis San Juan & 7 & 67 \\
\hline Pmis San Lorenzo & 4 & 26 \\
\hline Pmis San Luis & 8 & 109 \\
\hline Pmis San Luis Gonzaga & 1 & 23 \\
\hline Pmis San Mlguel & 11 & 240 \\
\hline Pmis San Nicolas & 3 & 74 \\
\hline Pmis Santo Tomé & 6 & 58 \\
\hline Pmis Sta. María la Mayor & 4 & 35 \\
\hline Pmis Yapeyú & 33 & 459 \\
\hline Río Paraná & 1 & 20 \\
\hline Río Uruguay & 9 & 62 \\
\hline Santa Fe & 319 & 3.662 \\
\hline Yancay & 33 & 246 \\
\hline Zárate & 1 & 2 \\
\hline Sub-total Litoral & 1.316 & 13.239 \\
\hline \multicolumn{3}{|l|}{ ATLANTICO SUR } \\
\hline Costas patagónicas & 31 & 272 \\
\hline Islas patagónicas & 1 & 10 \\
\hline Malvinas & 7 & 59 \\
\hline Carmen de Patagones & 6 & 167 \\
\hline Río Negro & 11 & 124 \\
\hline San José & 1 & 12 \\
\hline San Julián & 9 & 51 \\
\hline Sub-total Atlántico sur & 66 & 695 \\
\hline Total & 12.479 & 64.694 \\
\hline
\end{tabular}




\section{Apéndice 2. Mapas}

Mapa 1. Puntos alcanzados por la circulación extra-regional

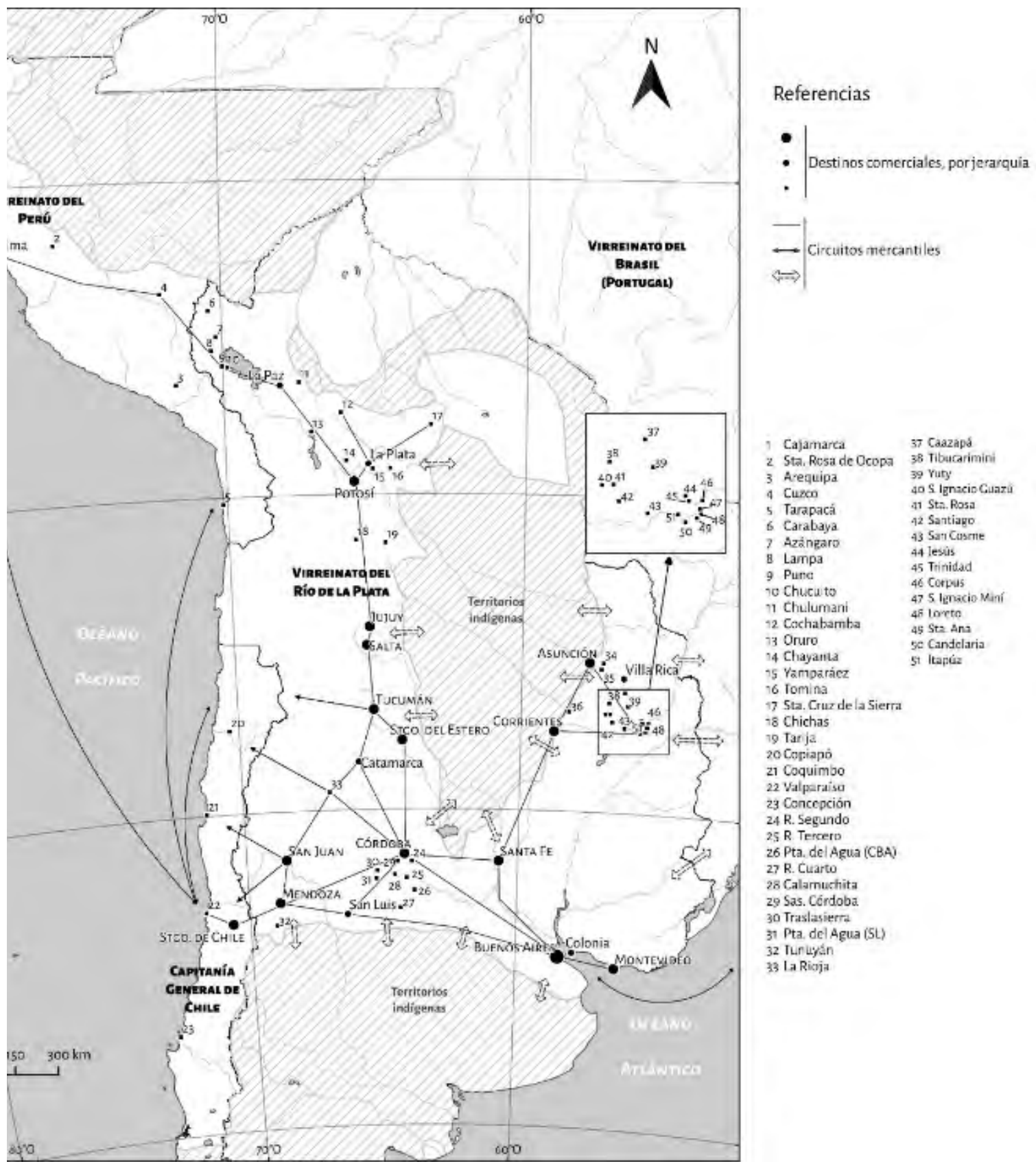

Fuente: RegAduAR. Elaboración: Lic. Tomás Guzmán. 
Mapa 2. Puntos alcanzados por la circulación intra-regional

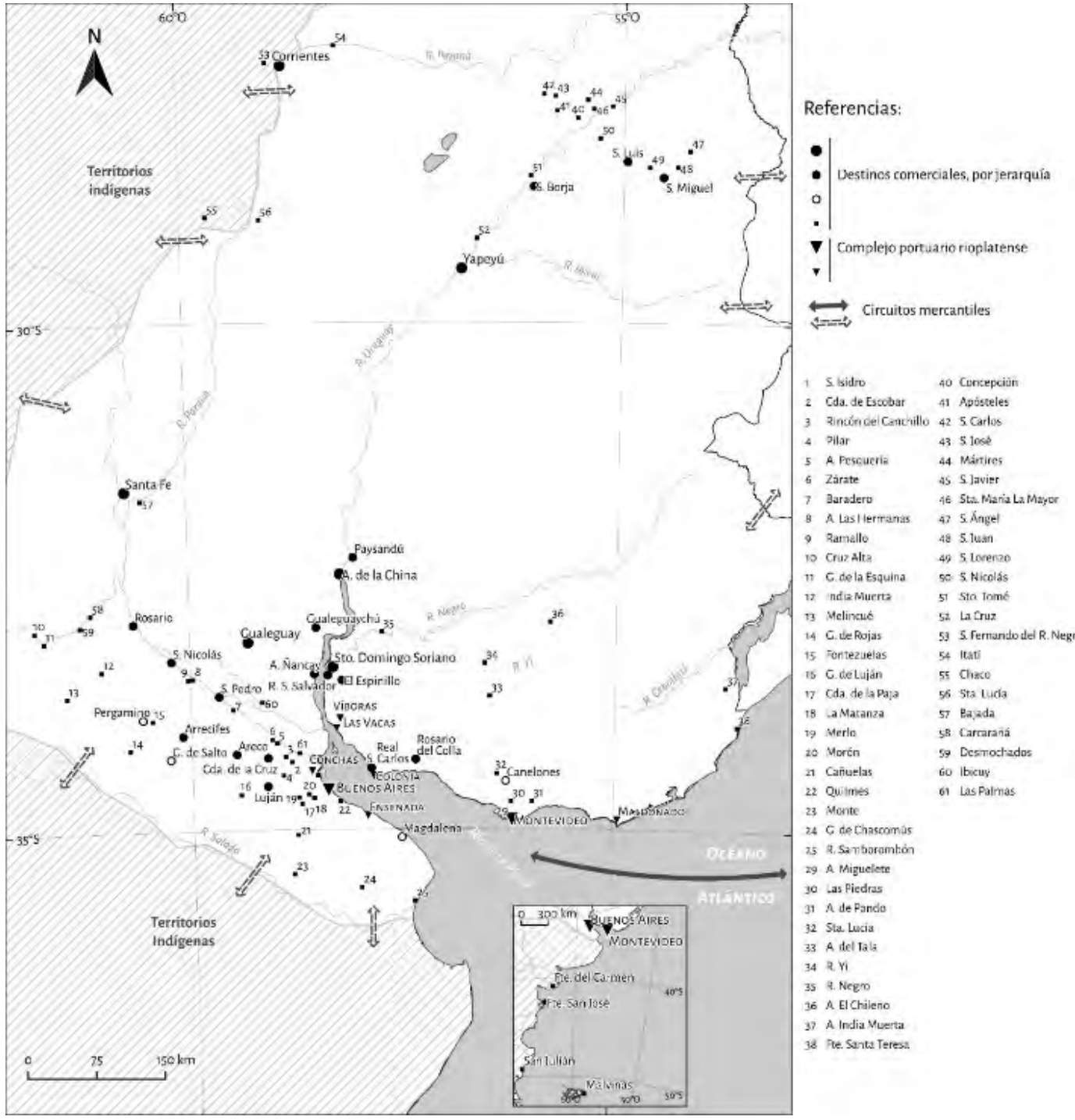

Fuente: RegAduAR. Elaboración: Lic. Tomás Guzmán. 
Mapa 3. Virreinato del Río de la Plata y sus intendencias

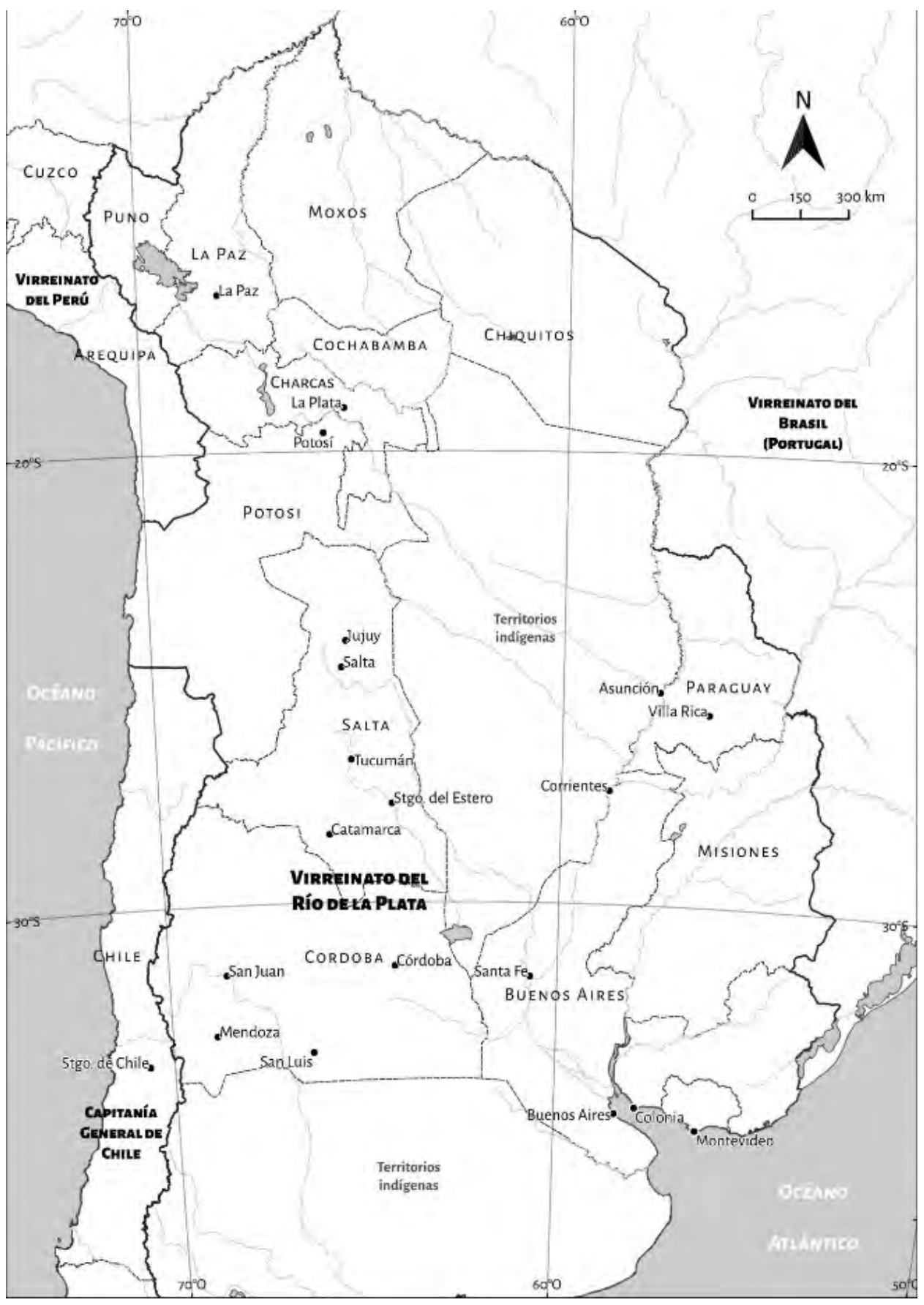

Elaboración: Lic. Tomás Guzmán. 
Fernando Jumar

\section{Bibliografía}

Acebal, Maximiliano, "Caminos del río Paraguay: Asunción y sus áreas de influencia económica, 1779-1783”, en 6tas. Jornadas de Historia Económica, Asociación Uruguaya de Historia Económica, Montevideo, 2-4 de diciembre de 2015.

Amadori, Arrigo, Negociando la obediencia. Gestión y reforma de los virreinatos americanos en tiempos del conde-duque Olivares (1621-1643), Madrid, CSIC, 2013.

Amaral, Samuel, “Comercio libre y economías regionales. San Juan y Mendoza, 1780-1820”, en Jahrbuch für Geschichte von Staat, Wirtschaft und Gesellschaft Lateinamerikas, 27, 1990, pp. 1-67.

Artola, Miguel, “América en el pensamiento español del siglo XVIII”, en Instituto Gonzalo Fernández de Oviedo, Homenaje a D. Ciriaco Pérez-Bustamante, Madrid, CSIC, 1969, pp. 51-78.

Assadourian, Carlos Sempat \& Palomeque, Silvia, "Las relaciones mercantiles de Córdoba (18001830). Desarticulación y desmonetización del mercado interno colonial en el nacimiento del espacio económico nacional”, en María Alejandra Irigoin; Roberto Schmit (Eds.), La desintegración de la economía colonial. Comercio y moneda en el interior del espacio colonial (180o-186o), Buenos Aires, Biblos, 2003, pp. 151-225.

Assadourian, Carlos Sempat \& Palomeque, Silvia, "Los circuitos mercantiles del "interior argentino" y sus transformaciones durante la guerra de la independencia (1810-1825)", en Bandieri, Susana (Coord.), La Historia económica y los procesos de independencia en la América Hispana, Buenos Aires, AAHE-Prometeo Libros, 2010, pp. 49-70.

Assadourian, Carlos Sempat, El sistema de la economía colonial. El mercado interior, regiones y espacio económico, Lima, IEP, 1982.

Belinberg, Germán, "El «informe secreto» de Mateo Alemán sobre el trabajo forzoso en las minas de Almadén”, en Estudios de Historia Social: revista del Instituto de Estudios de Sanidad y Seguridad Social, 2-3, 1977, pp. 357-443.

Benigno, Francesco, Las palabras del tiempo. Un ideario para pensar históricamente, Madrid, Cátedra, 2013.

Bernal, Antonio-Miguel, Monarquía e Imperio, Historia de España, Volumen 3, Barcelona, Crítica/Marcial Pons, 2007.

Bianchi Villeli, Marcia, “Organizar la diferencia: prácticas de consumo en Floridablanca”, en Cuadernos del Sur, 35-36, 2007, pp. 375-406. 
Buscaglia, Silvana, "Indígenas, Borbones y enclaves coloniales. Las relaciones interétnicas en el fuerte San José durante su primera década de funcionamiento (Chubut, 1779-1789)", en Corpus. Archivos virtuales de la alteridad americana, 5, 1, 2015, pp. 1-38.

Carzolio, María Inés, "Estado, Estado moderno, cultura jurisdiccional y cultura constitucional”, en Dell'Ellicine, Eleonora; Francisco, Héctor; Miceli, Paola; Morín, Alejandro (Coords.), Pensar el Estado en las sociedades precapitalistas. Pertinencia, límites y condiciones del concepto de Estado, Los Polvorines, Universidad Nacional de General Sarmiento, 2012, pp. 125-138.

Casanueva, María Laura, "Un poblado patagónico con identidad Castellano-Leonesa. Nuestra Señora del Carmen de Patagones, s. XVIII”, en Hernandarias. Revista del Instituto Argentina de Cultura Hispánica de Córdoba, 6, 4, 2014, pp. 33-69.

Chaunu, Pierre, Sevilla y América, siglos XVI y XVII, Sevilla, Universidad de Sevilla, 1983.

Coatsworth, John H., "El Estado y la actividad económica colonial”, en Tandeter, Enrique (Dir.); Hidalgo Lehuedé, Jorge (Co-dir.), Procesos americanos hacia la redefinición colonial, Historia General de América Latina, Tomo IV, España, s/l, Ediciones de la UNESCO/Editorial Trotta, 2000, capítulo 14, pp. 300-323.

Conti, Viviana; Jumar, Fernando, "El impacto de la independencia en las articulaciones y desarticulaciones regionales: ensayo comparativo entre la región Río de la Plata y la región Salto-jujeña”, en Revista Estudios del ISHIR. Unidad Ejecutora en Red, Investigaciones Socio Históricas Regionales, Unidad Ejecutora en Red/CONICET, 2, 2, 2012, pp. 1-21, http://web2.rosario-conicet.gov.ar/ojs/index.php/revistaISHIR/article/view/123 (consulta 10/02/2019).

Contreras, Carlos, La ciudad del mercurio. Huancavelica, 1570-170o, Lima, Instituto de Estudios Peruanos, 1982.

De La Cruz-Vergara, Maribel, "Fluvial and maritime commerce through the Port of Cartagena de Indias as conciliatory element in the Viceroyalty of Nueva Granada's economy, 1780-1810, en The Latin Americanist, 60, 20, 2016, pp. 191-216, https://doi.org/10.1111/tla.12081 (consulta 16/11/2018).

Djenderedjian, Julio, "Economía y sociedad en la Arcadia criolla. Formación y desarrollo de una sociedad de frontera en Entre Ríos, 1750-1820”, Tesis de Doctorado inédita, Universidad de Buenos Aires, 2003.

Dobado González, Rafael, "El trabajo en las minas de Almadén, 1750-1855”, Tesis de doctorado inédita, Universidad Complutense de Madrid, 1989.

Garavaglia, Juan Carlos, “El comercio virreinal 1779-1784”, Tesis de Licenciatura inédita, Uni- 
versidad de Buenos Aires, 1970, http://repositorio.filo.uba.ar/bitstream/handle/filodigital/4206/uba_ffyl_t_1970_se_Garavaglia.pdf?sequence=3\&isAllowed=y （consulta 10/03/2019).

Garavaglia, Juan Carlos, "El Río de la Plata en sus relaciones atlánticas: una balanza comercial (1779-1784)”, en Garavaglia, Juan Carlos, Economía, sociedad y regiones, Buenos Aires, Ediciones de la Flor, 1987, pp. 65-117. Hay una edición previa del texto en: Moneda y crédito: revista de economía, 141, 1977, pp. 75-101.

García de León, Antonio, Tierra adentro, mar en afuera. El puerto de Veracruz y su litoral a sotavento, 1519-1821, México, Fondo de Cultura Económica/Gobierno del Estado de Veracruz/Universidad Veracruzana, 2011.

Gelman, Jorge; Moraes, María Inés, "Las reformas borbónicas y las economías rioplatenses: cambio y continuidad”, en Gelman, Jorge; Llopis, Enrique; Marichal, Carlos (Coords), Iberoamérica y España antes de las independencias, 1700-1820: crecimiento, reformas y crisis, México, Instituto de Investigaciones “Dr. José María Luis Mora”, 2014, pp. 31-74.

Grenier, Jean-Yves, “Modèles de la demande sous l'Ancien Régime”, en Annales ESC, 3, 1987, pp. 497-527.

Grenier, Jean-Yves, L'économie d'Ancien Régime. Un monde de l'échange et de l'incertitude, París, Alban Michel, 1996.

Halperin Donghi, Tulio, Revolución y guerra. Formación de una elite dirigente en la Argentina criolla, $1^{\text {a }}$ ed. 1972, $3^{\text {a }}$ ed., Buenos Aires, Siglo XXI Editores S.A., 2002.

Jumar, Fernando, “«Buscar la vida» en el Río de la Plata. Marcelino Callexas Sanz, 1757-1820”, en Illes i Imperis, 18, 2016, pp. 44-76, http://www.raco.cat/index.php/IllesImperis/article/ view/208050023/403427 (consulta 10/02/2019).

Jumar, Fernando, "El comercio ultramarino por el complejo portuario rioplatense y la economía regional, 1714-1778”, en Magallánica. Revista de Historia Moderna, 3, 5, 2016, pp. 171259, http://fh.mdp.edu.ar/revistas/index.php/magallanica/article/view/2006 (consulta 10/02/2019).

Jumar, Fernando, "El espacio colonial peruano en la historiografía sobre circulación mercantil", en História Ecônomica \& História de Empresas, 17, 2, 2014, pp. 475-534, http://www. abphe.org.br/revista/index.php/rabphe/issue/view/40 (consulta 03/02/2019).

Jumar, Fernando, "El mundo hispánico durante el Antiguo Régimen desde los circuitos mercantiles y el espacio económico rioplatense”, en Historia Crítica, 70, 2018, pp. 23-44, https:// doi.org/10.7440/histcrit70.2018.02 (consulta 15/01/2019). 
Jumar, Fernando, "El precio de la fidelidad. La Guerra de Sucesión en el Río de la Plata, los intereses locales y el campo Borbón”, en Molinié, Annie; Merle, Alexandra (Dirs.), L'Espagne et ses guerres. De la fin de la Reconquête aux guerres de l'Indépendance, París, Presses de l'Université Paris/Sorbonne, 2004, pp. 203-236, http://www.fuentesmemoria.fahce. unlp.edu.ar/libros/pm.9/pm.9.pdf (consulta 05/02/2019).

Jumar, Fernando, "El primer boom de la exportación de cueros y la sociedad local. Río de la Plata. Fines del siglo XVII, comienzos del siglo XVIII", en XXI Jornadas de Historia Económica, Asociación Argentina de Historia Económica/Universidad Nacional de Tres de Febrero, Caseros, 2008, http://www.fuentesmemoria.fahce.unlp.edu.ar/trab_eventos/ev.712/ ev.712.pdf (consulta 05/02/2019).

Jumar, Fernando, "En torno a la circulación observada desde la Aduana de Buenos Aires entre 17779 y 1783", en El Taller de la Historia, 12, en prensa.

Jumar, Fernando, "Lo que la revolución se llevó: la región Río de la Plata como espacio homogéneo", en Boletín del Instituto de Historia Argentina y Americana Dr. Emilio Ravignani, Tercera Serie, 33, 2011, pp. 141-148.

Jumar, Fernando, "Los comerciantes rioplatenses: su participación en el comercio legal español, 1720-1778”, en Fernando Jumar (Ed.), Mercantilismo y comercio en el mundo ibérico, Documentos de Trabajo 2, Facultad de Ciencias Jurídicas, Sociales y de la Comunicación, Buenos Aires, Universidad Argentina de la Empresa, 2002, pp. 5-28.

Jumar, Fernando. "Plumas en guerra. Argumentos y contrargumentos en torno a la independencia de las Provincias Unidas en Sud América y la naciente historiografía nacional argentina”, en Jornadas Bicentenario de la Independencia, Universidad Nacional de Tres de Febrero, Caseros, 29 y 30 de julio de 2016.

Jumar, Fernando; Biangardi, Nicolás; Bozzo, José; Orlowski, Sabrina; Querzoli, Roberto; Sandrín, María Emilia, "El comercio ultramarino y la economía local en el complejo portuario rioplatense. Siglo XVIII”, en Anuario IEHS, 21, 2006, pp. 235-254.

Jumar, Fernando; Kraselsky, Javier, "Las esferas del poder. Hacendados y comerciantes ante los cambios de la segunda mitad del siglo XVIII", en Anuario del Instituto de Historia Argentina, Universidad Nacional de La Plata, 7, 2007, pp. 31-58, http://www.memoria.fahce. unlp.edu.ar/art_revistas/pr.672/pr.672.pdf (consulta 03/02/2019).

Jumar, Fernando; Sandrín, María Emilia, "El gasto público como dinamizador de la economía local. Río de la Plata, en la primera mitad del siglo XVIII”, en Sánchez Santiró, Ernest (Coord.), El gasto público en los Imperios Ibéricos, siglo XVIII, México, Instituto Mora, 2015, pp. 205-272.

Kraselsky, Javier, “Las corporaciones mercantiles de Buenos Aires y los préstamos y donativos 
graciosos”, en Illes i Imperis, 18, 2016, pp. 107-134.

Kraselsky, Javier, "Las estrategias de los actores del Río de la Plata: las Juntas y el Consulado de comercio de Buenos Aires a fines del Antiguo Régimen (1748-1809)”, Tesis de Doctorado inédita, Universidad Nacional de La Plata, 2011, http://www.memoria.fahce.unlp.edu.ar/ tesis/te.447/te.447.pdf (consulta 10/11/2018).

Kuntz Ficker, Sandra. "Mundial, trasnacional, global: un ejercicio de clarificación conceptual de los estudios globales", en Nuevo Mundo Mundos Nuevos, Debates, 2014, DOI: 10.4000/ nuevomundo.66524 (consulta 02/02/2019).

López de Albornoz, Cristina, "Tiempos de cambio: producción y comercio en Tucumán (17701820)”, en Andes, 13, 2002, sin paginación (33 pp.), http://www.redalyc.org/articulo. oa?id=12701308 (consulta 12/03/2019).

Menéndez Navarro, Alfredo, "Un testimonio médico sobre las condiciones de vida y trabajo de los mineros de Almadén en la segunda mitad del siglo XVIII: el prólogo del Catástrofe morboso de las Minas Mercuriales de la Villa de Almadén del Azogue (1778) de José Parés y Franqués (+1798)”, en Dinamys: Acta Hispanica ad Medicinæ Scientiarumque Historiam Illustradam, 11, 1991, pp. 147-196.

Moriconi, Lidia, Política, piedad y jurisdicción. Cultura jurisdiccional en la Monarquía Hispánica. Liébana en los siglos XVI-XVIII, Rosario, Prohistoria, 2011.

Palomeque, Silvia, "Circuitos mercantiles de San Juan, Mendoza y San Luis. Relaciones con el «interior argentino», Chile y el Pacífico sur (1800-1810)", en Anuario IEHS, 21, 2006, pp. 255-281.

Palomeque, Silvia, "La circulación mercantil en las provincias del Interior argentino entre 1800 y 1810”, en Anuario IEHS, 4, 1989, pp. 131-210.

Paredes, Isabel, "El comercio de la subregión de Paraguay a fines del siglo XVIII", en XIII Jornadas Interescuelas/departamentos de Historia, Universidad Nacional del Comahue, San Carlos de Bariloche, 2009, http://cdsa.aacademica.org/ooo-008/610.pdf (consulta 10/02/2019).

Paredes, Isabel, "La carrera del Paraguay a fines del siglo XVIII”, en América Latina en la Historia Económica, 21, 1, 2014, pp. 66-91.

Paredes, Isabel, "Los transportistas asuncenos de la Carrera del Paraguay y sus relaciones comerciales con Buenos Aires", en XIV Jornadas Interescuelas/Departamentos de Historia, Universidad Nacional de Cuyo, Mendoza, 2013, https://www.aacademica.org/ooo010/264 (consulta 10/02/2019). 
Pérez Sarrión, Guillermo, La península comercial. Mercado, redes sociales y Estado en España en el siglo XVIII, Madrid, Marcial Pons Historia, 2012.

Pinzón Ríos, Guadalupe, Acciones y reacciones en los puertos del Mar del Sur. Desarrollo portuario del Pacífico novohispano a partir de sus políticas defensivas, 1713-1789, México, UNAM/Instituto Mora, 2011.

Povea Moreno, Isabel, "Retrato de una decadencia. Régimen laboral y sistema de explotación en Huancavelica, 1784-1814", Tesis de doctorado inédita, Universidad de Granada, 2011.

Punta, Ana Inés, Córdoba borbónica. Persistencias coloniales en tiempos de reformas (1750180o), 2da. edición, Córdoba, Universidad Nacional de Córdoba, 2010.

Quesada, Vicente G., El virreinato del Río de la Plata, 1776-1810. Apuntamientos crítico-históricos para servir en la cuestión de límites entre la República Argentina y Chile, Buenos Aires, Tipografía de M. Biedma, 1881.

Ramos Palencia, Fernando; Yun Casalilla, Bartolomé (Eds.), Economía política desde Estambul a Potosí. Ciudades-Estado, imperios y mercados en el mediterráneo y en el Atlántico ibérico, c. 120o-180o, Valencia, Universitat de València, 2012.

Romano, Silvia, “Córdoba y el intercambio regional, 1820-1855”, en Cuadernos de Historia, Serie Economía y Sociedad, 2, 1999, Universidad Nacional de Córdoba, Área de Historia del CIFFyH, 1999, p. 151-182, https://revistas.unc.edu.ar/index.php/cuadernosdehistoriaeys/ article/view/19694/19437 (consulta 05/02/2019).

Ruiz Ibáñez, José Javier, Las vecindades de las Monarquías Ibéricas, Madrid, Fondo de Cultura Económica, 2013.

Ruiz Torres, Pedro, Reformismo e Ilustración, Historia de España, Volumen 5, Barcelona, Crítica/Marcial Pons, 2008.

Sancci, Bruno, La colonización española en la Patagonia, Buenos Aires, De Los Cuatro Vientos, 2010.

Schaub, Jean-Frédéric, "Sobre el concepto de Estado", en Historia Contemporánea, 28, 2004, pp. 47-51.

Senatore, María Ximena, Arqueología e historia en la colonia española de Floridablanca. Patagonia, siglo XVIII, Buenos Aires, Editorial Teseo, 2007.

Serrato Higuera, Rubén Darío, "Las armas del dinero: mecanismos de financiación y administración en la segunda expedición de Pedro de Cevallos al Río de la Plata, 1777”, Tesis de 
Maestría inédita, Universidad Nacional de Tres de Febrero, 2017.

Serrato Higuera, Rubén Darío, Las armas del dinero. El estado fiscal-militar español del siglo XVIII, Saarbrücken, Editorial Académica Española, 2018.

Tenti de Laitán, María Mercedes, "El comercio de La Rioja y Santiago del Estero en la época virreinal”, en Nuevas Propuestas. Revista de la UCSE, 19, 1996, pp. 67-78.

Valle Pavón, Guillermina del, "Contraprestaciones por los servicios financieros del Consulado de México y sus miembros para la guerra contra Gran Bretaña, 1779-1783”, en Revista Complutense de Historia de América, 41, 2015, pp. 149-171.

Wentzel, Claudia, "Algunas consideraciones sobre el comercio de Buenos Aires con el Pacífico", Buenos Aires, inédito, 1989. 